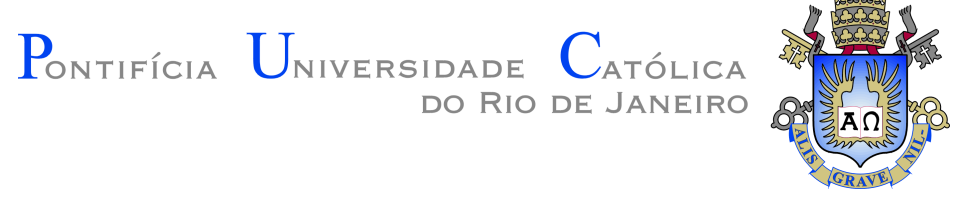

Raffael Russo

Monetary and Fiscal Policy in an Open
Economy: A Welfare-Based Approach

\begin{abstract}
Dissertação de Mestrado
Dissertation presented to the Programa de Pós-graduação em Economia da PUC-Rio in partial fulfillment of the requirements for the degree of Mestre em Economia.
\end{abstract}

Advisor : Prof. Tiago Berriel

Co-advisor: Prof. Yvan Bécard

Rio de Janeiro

May 2020 


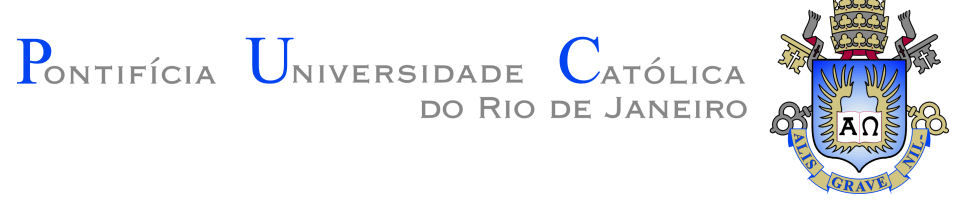

Raffael Russo

\section{Monetary and Fiscal Policy in an Open Economy: A Welfare-Based Approach}

Dissertation presented to the Programa de Pós-graduação em Economia da PUC-Rio in partial fulfillment of the requirements for the degree of Mestre em Economia. Approved by the Examination Committee.

Prof. Tiago Berriel

Advisor

Departamento de Economia - PUC-Rio

Prof. Yvan Bécard

Co-advisor

Departamento de Economia - PUC-Rio

Prof. Eduardo Zilberman

Departamento de Economia - PUC-Rio

Prof. Marco Bonomo

Faculdade de Economia - Insper

Rio de Janeiro, May the 4th, 2020 
All rights reserved.

\section{Raffael Russo}

B.A. in Computer Engineering, Instituto Militar de Engenharia (IME), 2016.

Russo, Raffael

Monetary and Fiscal Policy in an Open Economy: A Welfare-Based Approach / Raffael Russo; advisor: Tiago Berriel; co-advisor: Yvan Bécard. - Rio de janeiro: PUC-Rio, Departamento de Economia, 2020.

v., 45 f: il. color. ; $30 \mathrm{~cm}$

Dissertação (mestrado) - Pontifícia Universidade Católica do Rio de Janeiro, Departamento de Economia.

Inclui bibliografia

1. Economia - Teses. 2. Macroeconomia - Teses. 3. Bemestar;. 4. Política Monetária;. 5. Política Fiscal;. 6. Economia Aberta;. 7. Modelo Novo Keynesiano. I. Berriel, Tiago. II. Bécard, Yvan. III. Pontifícia Universidade Católica do Rio de Janeiro. Departamento de Economia. IV. Título. 
To God, for we are the way He uses to understand Himself. 


\section{Acknowledgments}

I thank God and the Universe for guiding me through a path of self-knowledge and love.

I thank my friends, for they are my family and without them nothing of this would be possible.

I thank my advisors, for they truly paved the way for lessons I had to learn, beyond the academic perspective.

I thank my grandmother and my girlfriend for turning my house into a home and giving me love and calmness to achieve my goals.

I thank PUC-Rio and the Economics Department, for every person that touched my life contributed to making this a unique journey.

Financial suppport from CAPES and FAPERJ is gratefully acknowledged. This study was financed in part by the Coordenação de Aperfeiçoamento de Pessoal de Nível Superior and the Fundação de Amparo à Pesquisa do Estado do Rio de Janeiro. 


\section{Abstract}

Russo, Raffael; Berriel, Tiago (Advisor); Bécard, Yvan (CoAdvisor). Monetary and Fiscal Policy in an Open Economy: A Welfare-Based Approach. Rio de Janeiro, 2020. 45p. Dissertação de mestrado - Departamento de Economia, Pontifícia Universidade Católica do Rio de Janeiro.

In this paper, we present a New Keynesian two-country open economy model featuring distortionary taxation and stochastic government spending. Within this modeling we compare, in a welfare-sense, different fiscal and monetary rules with a benchmark constituted by a cooperative Ramseypolicy equilibrium.

\section{Keywords}

Welfare; Monetary Policy; Fiscal Policy; Open Economy; New Keynesian Model 


\section{Resumo}

Russo, Raffael; Berriel, Tiago; Bécard, Yvan. Política Monetária e Fiscal em uma Economia Aberta: Abordagem baseada em Bem-Estar. Rio de Janeiro, 2020. 45p. Dissertação de Mestrado - Departamento de Economia, Pontifícia Universidade Católica do Rio de Janeiro.

Nesse artigo, apresentamos um modelo Novo Keynesiano de economia aberta com dois países, taxação distorciva e gasto governamental estocástico. Nessa modelagem comparamos, em uma base de bem-estar, diferentes regras monetária e fiscal com uma referência constituída pelo equilíbrio cooperativo da política de Ramsey.

\section{Palavras-chave}

Bem-estar; Política Monetária; Política Fiscal; Economia Aberta; Modelo Novo Keynesiano 


\section{Table of contents}

1 Introduction $\quad 12$

2 The Model $\quad 16$

2.1 Aggregated Variables 16

$\begin{array}{lll}2.2 \text { Households } & 18\end{array}$

$\begin{array}{lll}2.3 & \text { Firms } & 19\end{array}$

2.4 Government Budget Constraint 20

2.5 Market Clearing 21

2.6 Equilibrium 22

2.7 Social-Planner's Problem 22

3 Specifications and Implementation $\quad 24$

3.1 Calibration 24

3.2 Monetary and Fiscal Policy Rules 25

$\begin{array}{ll}3.3 \text { Welfare Measures } & 26\end{array}$

$\begin{array}{ll}3.4 & \text { Implementation } \\ \end{array}$

4 Results $\quad 29$

$\begin{array}{lll}4.1 & \text { Ramsey-problem } & 29\end{array}$

4.2 Simple Rules 31

5 Conclusion $\quad 35$

$\begin{array}{ll}\text { A Appendix } & 38\end{array}$

$\begin{array}{lll}\text { A.1 Aggregation } & 38\end{array}$

A.2 Equilibrium $\quad 40$

A.3 Ramsey-problem mathematically 41

A.4 Steady State $\quad 42$

A.5 Robustness Exercise 43 


\section{List of figures}

Figure 4.1 Ramsey-problem IRFs 29

Figure 4.2 Ramsey-problem IRFs 30

Figure 4.3 Simple Rules IRFs 34

Figure 4.4 Simple Rules IRFs 34

Figure A.1 IRFs when welfare is given by (3-11) - Distortionary-tax case 44

Figure A.2 IRFs when welfare is given by (3-11) - Distortionary-tax case 44

Figure A.3 IRFs when welfare is given by (3-11) - Lump-sum case 45

Figure A.4 IRFs when welfare is given by (3-11) - Lump-sum case 45 


\section{List of tables}

Table 3.1 Summary of Parameters Calibration 25

Table 4.1 Results of different specifications 32 


\section{List of Abreviations}

IRF - Impulse Response Function

CPI - Consumer Price Index

GDP - Gross Domestic Product 


\section{Introduction}

The open economy environment has become academic interest since the increasing interrelation of economies. In fact, it is well established that policy coordination among countries and spillovers of shocks is an economic concern. This scenario, alone, motivates a model that could address these effects in a general setting. Bringing our point to concrete cases we see that in episodes such as the 2008 crisis, countries experienced shocks in distinct degrees of severity, calling for different monetary and fiscal policy responses; in the the Brexit, international policy coordination became a rich environment for economic discussion, being important for a nation's welfare. Questions such as: "How will be coordination between England and European Union?" or "Will there be coordination from now on?" came to light.

In this context a question that arises is: how should countries engage in monetary and fiscal policy to attain maximum union-wide welfare when both policies are independent for each country? Also, how does the optimal response relates with simple implementable rules in a welfare-sense?

This paper targets these questions adding to the literature on open economy, optimal policies and welfare comparison. We analyze an environment featuring two countries of equal size, distortionary taxation and supply shocks, thus, filling a gap in the literature that mainly focuses on small open economies or monetary-unions and, for the most part, on the dynamics of monetary policy, disregarding distortionary fiscal policy. ${ }^{1}$

To that end we present a New Keynesian two-country open economy model featuring income-taxation, non-state-contingent nominal debt, stochastic government spending and technology shocks. First we numerically find the Ramsey-policy under sticky prices and then we compare it with cases where simple rules for taxation and nominal interest rate are set for each country.

From a methodological perspective our approach is characterized by being simple in its presentation and derivation of the results. In fact, we define the equations and the problems we solve only non-linearly. Within this moddeling we compute the Ramsey-policy under sticky-prices and explain the mechanism behind this response. Also, we simulate a simple-rules economy,

\footnotetext{
${ }^{1}$ We review the literature in later paragraphs.
} 
describing how it works and mimics - up to a point - the Ramsey-policy. Therefore we analyze theoretical and implementable mechanisms trough which the economy works. We do not attain ourselves only on dynamics, but also perform a welfare-comparison between the Ramsey-policy and the simple-rules economy. To that end we adapt a measure of welfare-cost from Heathcote et al. (2011) to develop our own code that measures how close the specifications are.

The simple rules are defined as linear relations between the instruments - taxes and nominal interest rates - and aggregates - debt, output and inflation -. We develop a grid-search-code to find the values of the parameters in each specification that maximize conditional welfare of the economy. ${ }^{2}$ These exercises are done both under cooperation and non-cooperation of the authorities and for the latter we codify a recursive routine. ${ }^{3}$

Results are that the Ramsey-policy response features a permanent deviation from steady-state for taxes, debt, output and the terms of trade; and that it is best to lower taxes in home country and raise taxes in foreign country, managing the terms of trade so as to exacerbate its depreciation (compared to a lump-sum tax case), channeling demand to the home country and raising world welfare. Among simple rules, it is better, in a cooperative welfare-sense, for home country to respond to foreign country inflation-gap (deviation of inflation from steady-state value); if home response to foreign country inflation-gap hits an upperbound (defined exogenously for purpose of economic interpretation) than it is second best to respond to foreign country output-gap; fiscal policy response is slightly stronger in foreign country than in home country. This indicates that home tax-rate has a main impact on the terms of trade, in the sense that as its inertial component is higher, home tax-rate manages the terms of trade for more periods. Finally, in a non-cooperative setting countries rely more on monetary policy than on fiscal policy, being concerned with the distortionary nature of the latter.

In what pertains the related literature, from the perspective of optimal policies there is work for closed economy models such as Chari et al. (1991), Barro (1979), Aiyagari et al. (2002), Siu (2004) that mainly discuss the optimal processes that tax and inflation follow after a shock, and for open economy, namely Benigno and De Paoli (2006) and Ferrero (2009) that focus additionally in optimal exploitation of the terms of trade. Together they pave the way for a deeper understanding and discussion of our findings. Chari et al. (1991) find that a closed economy flexible-price environment, after a government spending shock, state-contingent gains on debt are possible by varying inflation, also

\footnotetext{
${ }^{2} \mathrm{By}$ conditional welfare, we mean the welfare conditional on the initial period of the simulation being the steady-state of the economy.

${ }^{3}$ Explained in session 3.4
} 
income-tax is roughly constant; this result was obtained considering emission of state-contingent nominal debt in a cashless model or in a monetary model with non-state-contingent nominal debt, where real gains were possible. Barro (1979) and Aiyagari et al. (2002) in similar environments as the previous one, but with non-state-contingent real debt, find that optimal taxation follows a random-walk process. In fact, in these models it is optimal to smooth taxes over time and across states of nature because taxation creates inefficiencies on households allocation of consumption and leisure. Siu (2004), in a stickyprice model, finds, considering emission of nominal non-state-contingent debt, near-random-walk behavior for optimal taxes after a low-volatility government spending shock and little inflation volatility due to misallocation of real resources induced by relative price distortions. ${ }^{4}$.

In open-economy models there is an incentive to manage the terms of trade, both by using distortionary taxation or inflation as tools (the last one in sticky-price models). Indeed, as there is a cost for inflation, Benigno and De Paoli (2006) find, for a small open economy, that it is optimal for home country to vary taxes over time and across states of nature to manage the terms of trade. ${ }^{5}$ After a positive home productivity shock, they argue that higher home income-tax appreciates the real exchange rate (or the terms of trade) so that home disutility of labour is lowered but home utility of consumption is not, because agents can rely on foreign produced goods. They find that, optimally, taxes follow a non-stationary process and that debt, output and real exchange rate levels face a permanent change after a supply shock. Our findings for the managing of the terms of trade are different from theirs due to the symmetric size of the countries in our economy. Also we focus on welfare-comparison of different specifications.

Finally, Ferrero (2009) assesses optimal fiscal and monetary policies in a monetary-union model, after government spending shocks. She performs a welfare-comparison, in a cooperative scenario, between this setup and optimal simple rules. Despite being similar to our economy, she focuses on the comparison of rules that precludes a constant value of government debt versus rules with variable government debt, disregarding own-country monetary asymmetries and non-cooperation. After a supply shock, she also finds as the optimal policy a permanent adjustment of both debt and terms of trade levels and that taxes follow a process similar to a random-walk.

In the context of welfare-based evaluations works such as Parrado and Velasco (2002) compares different monetary policy rules in small open economy

${ }^{4}$ In fact Siu (2004) argues that the sticky-price induced conditions are similar to the one induced by incomplete-markets featured in Aiyagari et al. (2002)

${ }^{5}$ They call it the terms of trade externality. 
environment. They find that its better to target domestic inflation than CPI and that flexible exchange rate regime outperforms managed exchange rates. Therefore the focus of their paper is different than ours. The exercise we perform resembles the one in Schmitt-Grohé and Uribe (2006), that compares, from a closed economy perspective, monetary and fiscal rules with a benchmark, constituted by the flexible-price Ramsey-equilibrium and define a measure of welfare-cost. Our paper differs from the previous approach because our benchmark is the Ramsey-policy with sticky-prices and we define and calculate numerically a different notion of welfare-cost. ${ }^{6}$

This paper is organized as follows: section 2 introduces the basic model, a definition of the equilibrium and the social-planner's problem; section 3 presents specifications and computation methods such as welfare measures, rules and parameters calibration; section 4 presents the results after a technology shock, such as impulse response functions (IRFs) and the welfare-costs associated with optimal simple rules with respect to the Ramsey-allocation; section 5 concludes. Appendix A contains the definition of aggregating variables; Appendix B contains a formal definition of the equilibrium; Appendix $\mathrm{C}$ contains the definition of the Ramsey-problem; Appendix D defines the steady-state of the economy and Appendix E presents a robustness test we performed.

${ }^{6} \mathrm{We}$ believe that it is more intuitive to compare simple rules in a sticky-price environment with the Ramsey-policy with sticky-prices. 


\section{2}

\section{The Model}

Here we present the main equations of the model. There are two countries with measure 1 , home and foreign. foreign variables will be denoted with a $" * "$ above them. We assume that there is a complete set of state-contingent international assets which allows for perfect risk sharing among countries.

\section{1}

\section{Aggregated Variables}

We denote the utility of a representative infinitely lived home household evaluated from date 0 as:

$$
\mathcal{U}_{0}=\mathbb{E}_{0} \sum_{0}^{\infty} \beta^{t}\left(U\left(C_{t}\right)-V\left(N_{t}\right)+J\left(G_{t}\right)\right)
$$

where $U$ represents the utility of the composite home consumption bundle $C_{t}$; $V$ represents disutility of labour supply $N_{t}$; and $J$ represents utility of the government's supply of public good $G_{t} .{ }^{1}$ For the foreign economy we have the same functions, with a "*" above each variable. We assume that period 0 government debt is held only by own country agents, as in Nakajima (2008). In that case, composite consumption and prices are defined by:

$$
\begin{aligned}
C_{t} & =\left(\frac{C_{H, t}}{\frac{\nu}{2}}\right)^{\frac{\nu}{2}}\left(\frac{C_{F, t}}{1-\frac{\nu}{2}}\right)^{1-\frac{\nu}{2}} \\
C_{t}^{*} & =\left(\frac{C_{H, t}^{*}}{1-\frac{\nu}{2}}\right)^{1-\frac{\nu}{2}}\left(\frac{C_{F, t}^{*}}{\frac{\nu}{2}}\right)^{\frac{\nu}{2}} \\
P_{t} & =\left(P_{H, t}\right)^{\frac{\nu}{2}}\left(P_{F, t}\right)^{1-\frac{\nu}{2}} \\
P_{t}^{*} & =\left(P_{F, t}^{*}\right)^{\frac{\nu}{2}}\left(P_{H, t}^{*}\right)^{1-\frac{\nu}{2}}
\end{aligned}
$$

where we consider the elasticity of substitution between domestic and foreign goods equal to one; $\nu<2$ denotes the degree of trade openness. For the exercises proposed we consider full-openness, with $\nu=1 .^{2}$. Here, $C_{H}$ and $C_{F}$ are home agent's composite consumption bundles of home and foreign

${ }^{1}$ As usual $U$ and $J$ are differentiable and concave in $C$ and $G$, respectively, while $V$ is differentiable and convex in $N$.

${ }^{2}$ To have home bias, for example, one should impose $\nu>1$. The case where $\nu=2$ represents a closed economy. 
differentiated goods, respectively. Home good $i$ has price $P_{H, t}(i)$ in the home country, and foreign good $j$ has price $P_{F, t}(j)$ in the home country. By solving the standard aggregation problems presented in Appendix A we find that:

$$
\begin{aligned}
C_{H, t} & =\frac{\nu}{2} \frac{P_{t}}{P_{H, t}} C_{t} \\
C_{F, t} & =\left(1-\frac{\nu}{2}\right) \frac{P_{t}}{P_{F, t}} C_{t}
\end{aligned}
$$

and the analogous for the foreign economy:

$$
\begin{aligned}
C_{H, t}^{*} & =\left(1-\frac{\nu}{2}\right) \frac{P_{t}^{*}}{P_{H, t}^{*}} C_{t}^{*} \\
C_{F, t}^{*} & =\frac{\nu}{2} \frac{P_{t}^{*}}{P_{F, t}^{*}} C_{t}^{*}
\end{aligned}
$$

For the government spending we consider that each government only buys goods from its own country. So we define $G_{t}$ as the aggregate purchases of the government. Also, we have that $g_{t}(i)$ is the government consumption of home good $i$, such that we define:

$$
G_{t}=\left(\int_{0}^{1} g_{t}(i)^{\frac{\theta-1}{\theta}} d i\right)^{\frac{\theta}{\theta-1}}
$$

The variable $\theta>1$ is the elasticity of substitution between home (and also foreign) goods. Solving the government maximization problem we find:

$$
g_{t}(i)=\left(\frac{P_{H, t}(i)}{P_{H, t}}\right)^{-\theta} G_{t}
$$

and for the foreign economy:

$$
g_{t}^{*}(i)=\left(\frac{P_{F, t}^{*}(i)}{P_{F, t}^{*}}\right)^{-\theta} G_{t}^{*}
$$

Finally, We assume that the Law of One Price holds:

$$
P_{j, t}(i)=\phi_{t} P_{j, t}^{*}(i) \quad \forall \quad j \in\{H, F\}, \quad i \in[0,1]
$$

where $\phi_{t}$ is the nominal exchange rate. We also define the home terms of trade as:

$$
S_{t}=\frac{P_{F, t}}{P_{H, t}}=\frac{P_{F, t}^{*}}{P_{H, t}^{*}}
$$




\section{2}

\section{Households}

Households choose consumption $C_{t}$, hours worked $N_{t}$ and the portfolio of one-period state-contingent bonds $B_{t+1}$. Also, we have that $Q_{t, t+1}$ is the stochastic discount factor between dates $t$ and $t+1$ for nominal payoffs in the home country. Households maximize (2-1) subject to the following budget constraint:

$P_{t} C_{t}+\mathbb{E}_{t}\left\{Q_{t, t+1} B_{H, t+1}\right\}+\phi_{t} \mathbb{E}_{t}\left\{Q_{t, t+1}^{*} B_{F, t+1}\right\}=B_{H, t}+\phi_{t} B_{F, t}+\left(1-\tau_{t}\right) W_{t} N_{t}+\Gamma_{t}-T_{t}$

In which $\Gamma_{t}=\int_{0}^{1} \Gamma_{t}(i) d i$ is per-capita aggregate profit of the firms, and $T_{t}$ is a lump-sum transfer used only to offset steady-state distortions; ${ }^{3} \Gamma_{t}(i)$ is the profit of firm $i ; \tau_{t}$ is the income tax percentage paid to the government; and $W_{t}$ is aggregate nominal wage. We also describe the natural debt limit of the agent as:

$$
-\left(B_{H, t}+\phi_{t} B_{F, t}\right) \leq \sum_{s=t}^{\infty} \mathbb{E}_{t}\left\{Q_{t, s}\left[\left(1-\tau_{s}\right) W_{s} N_{s}+\Gamma_{s}\right]\right\}
$$

where $Q_{t, a}=\prod_{s=t+1}^{a} Q_{s-1, s}$. The optimal conditions of the households problem are then:

$$
\begin{aligned}
& \frac{U_{c}\left(C_{t}\right)}{V_{n}\left(N_{t}\right)}=\frac{P_{t}}{\left(1-\tau_{t}\right) W_{t}} \\
& \mathbb{E}_{t} Q_{t, t+1}=\beta \mathbb{E}_{t}\left\{\frac{U_{c}\left(C_{t+1}\right)}{U_{c}\left(C_{t}\right)} \frac{P_{t}}{P_{t+1}}\right\} \\
& \mathbb{E}_{t}\left\{Q_{t, t+1}^{*} \frac{\phi_{t}}{\phi_{t+1}}\right\}=\beta \mathbb{E}_{t}\left\{\frac{U_{c}\left(C_{t+1}\right)}{U_{c}\left(C_{t}\right)} \frac{P_{t}}{P_{t+1}}\right\}
\end{aligned}
$$

such that $R_{t}=\left\{E_{t}\left\{Q_{t, t+1}\right\}\right\}^{-1}$ denotes the gross nominal yield on a oneperiod discount bond. For the foreign economy we have analogous conditions of (2-2)-(2-4). Under complete markets for state-contingent assets the efficiency condition for bonds holdings by residents in foreign economy is:

$$
\begin{aligned}
& \mathbb{E}_{t} Q_{t, t+1}^{*}=\beta \mathbb{E}_{t}\left\{\frac{U_{c}\left(C_{t+1}^{*}\right)}{U_{c}\left(C_{t}^{*}\right)} \frac{P_{t}^{*}}{P_{t+1}^{*}}\right\} \\
& \mathbb{E}_{t}\left\{Q_{t, t+1} \frac{\phi_{t+1}}{\phi_{t}}\right\}=\beta \mathbb{E}_{t}\left\{\frac{U_{c}\left(C_{t+1}^{*}\right)}{U_{c}\left(C_{t}^{*}\right)} \frac{P_{t}^{*}}{P_{t+1}^{*}}\right\} \\
& R_{t}^{*}=\left\{\mathbb{E}_{t}\left\{Q_{t, t+1} \frac{\phi_{t+1}}{\phi_{t}}\right\}\right\}^{-1}
\end{aligned}
$$

${ }^{3}$ We modelled and undistorted steady-state to isolate the effects of distortionary taxation, monopolistic competition and sticky-prices only to the dynamics of the economy. 
Also, the assumption of complete markets for state-contingent assets implies that state-contingent nominal marginal utility is equated across countries. Which leads to:

$$
\frac{U_{c}\left(C_{t}^{*}\right)}{U_{c}\left(C_{t}\right)}=\frac{\phi_{t} P_{t}^{*}}{P_{t}} \equiv \varphi_{t}
$$

Such that $\varphi_{t}=S_{t}^{\nu-1}$ is the real exchange rate.

\section{3}

Firms

We assume that each firm $i$ is monopolistic and produces a differentiated good according to:

$$
Y_{t}(i)=A_{t} N_{t}(i) \quad Y_{t}^{*}(i)=A_{t}^{*} N_{t}^{*}(i)
$$

such that

$$
N_{t}=\int_{0}^{1} N_{t}(i) d i \quad N_{t}^{*}=\int_{0}^{1} N_{t}^{*}(i) d i
$$

and

$$
Y_{t}(i)=\left(\frac{P_{H, t}(i)}{P_{H, t}}\right)^{-\theta} Y_{t} \quad Y_{t}^{*}(i)=\left(\frac{P_{F, t}^{*}(i)}{P_{F, t}^{*}}\right)^{-\theta} Y_{t}^{*}
$$

which takes us to the relations:

$$
N_{t}=\frac{\int_{0}^{1} P_{H, t}(i)^{-\theta} d i}{P_{H, t}^{-\theta}} \frac{Y_{t}}{A_{t}} \quad N_{t}^{*}=\frac{\int_{0}^{1} P_{F, t}^{*}(i)^{-\theta} d i}{P_{F, t}^{*}-\theta} \frac{Y_{t}^{*}}{A_{t}^{*}}
$$

where we define $V_{t}=\frac{\int_{0}^{1} P_{H, t}(i)^{-\theta} d i}{P_{H, t}^{-\theta}}$ and $V_{t}^{*}=\frac{\int_{0}^{1} P_{F, t}^{*}(i)^{-\theta} d i}{P_{F, t}^{*}{ }^{-\theta}}$ as the price dispersion variables, and $A_{t}, A_{t}^{*}$ are productivity parameters that follow:

$$
\begin{aligned}
& \ln \left(A_{t}\right)=\rho_{A} \ln \left(A_{t-1}\right)+\epsilon_{A} \\
& \ln \left(A_{t}^{*}\right)=\rho_{A}^{*} \ln \left(A_{t-1}^{*}\right)+\epsilon_{A}^{*}
\end{aligned}
$$

where $\epsilon_{A}$ and $\epsilon_{A}^{*}$ are white noise. For a home Firm, profits are

$$
\Gamma_{t}(i)=P_{H, t}(i) Y_{t}(i)-(1-\chi) W_{t} N_{t}(i)
$$

where $\chi$ is a subsidy financed by lump-sum tax to eliminate steady-state firstorder inefficiencies. ${ }^{4}$ We consider that each firm resets its price according

${ }^{4}$ We find the optimal value for $\chi$ in appendix $\mathrm{C}$ 
to Calvo pricing with probability of adjusting prices equal to $1-\kappa$. Firms that adjust their price set a new price given by $\tilde{P}_{H, t}(i)$. By having $Q_{t, t+j}=$ $\beta^{j} \frac{U_{c}\left(C_{t+j}\right)}{U_{c}\left(C_{t}\right)} \frac{P_{t}}{P_{t+j}}$ the firm that readjusts its price at time t solves:

$$
\begin{aligned}
\max _{\tilde{P}_{H, t}(i)} \sum_{j=0}^{\infty} \kappa^{j} \mathbb{E}_{t}\left\{Q_{t, t+j}\left[\tilde{P}_{H, t}(i) Y_{t+j \mid t}(i)-W_{t+j} N_{t+j \mid t}(i)(1-\chi)\right]\right\} \Longleftrightarrow \\
\Longleftrightarrow \max _{\tilde{P}_{H, t}(i)} \sum_{j=0}^{\infty} \kappa^{j} \mathbb{E}_{t}\left\{Q_{t, t+j}\left(\frac{\tilde{P}_{H, t}(i)}{P_{H, t+j}}\right)^{-\theta} Y_{t+j}\left[\tilde{P}_{H, t}(i)-\frac{W_{t+j}}{A_{t+j}}(1-\chi)\right]\right\}
\end{aligned}
$$

which leads us to the optimal condition:

$$
\tilde{P}_{H, t}(i)=\frac{\sum_{j=0}^{\infty} \kappa^{j} \frac{Q_{t, t+j} Y_{t+j}}{P_{H, t+j}^{-\theta}} \frac{W_{t+j}}{A_{t+j}}(1-\chi) \frac{\theta}{\theta-1}}{\sum_{j=0}^{\infty} \kappa^{j} \frac{Q_{t, t+j} Y_{t+j}}{P_{H, t+j}^{-\theta}}}
$$

Finally, we have that

$$
P_{H, t}=\left[(1-\kappa) \tilde{P}_{H, t}^{1-\theta}+\kappa P_{H, t-1}^{1-\theta}\right]^{\frac{1}{1-\theta}}
$$

\section{4}

\section{Government Budget Constraint}

We assume that households have access to both home and foreign nominal government bonds, that pays respectively an interest rate of $R_{t}$ and $R_{t}^{*}$ in all states of the world. Governments cannot buy each other's debt. The lump-sum tax and the subsidy offset each other. Following Benigno and De Paoli (2006), the government's budget constraint is:

$$
\begin{aligned}
D_{t} & =R_{t-1} D_{t-1}+\int_{0}^{1} P_{H, t}(i) g_{t}(i) d i-\tau_{t} W_{t} N_{t}+\underbrace{\left(\chi W_{t} N_{t}-T_{t}\right)}_{=0} \Rightarrow \\
\Rightarrow D_{t} & =P_{H, t} G_{t}+R_{t-1} D_{t-1}-\tau_{t} W_{t} N_{t}
\end{aligned}
$$

Where $D_{t}$ is per-capita debt. Now define $D_{t}^{\text {Norm }} \equiv \frac{D_{t} R_{t}}{P_{t}}$ and we have:

$$
D_{t}^{n o r m}=R_{t} S_{t}^{\frac{\nu}{2}-1}\left(\frac{D_{t-1}^{n o r m} S_{t-1}^{1-\frac{\nu}{2}}}{\Pi_{H, t}}+G_{t}-\tau_{t} w_{t} N_{t}\right)
$$

where $w_{t}=\frac{W_{t}}{P_{H, t}}$. For the foreign economy we have the analogous: ${ }^{5}$

$$
D_{t}^{*, \text { norm }}=R_{t}^{*} S_{t}^{1-\frac{\nu}{2}}\left(\frac{D_{t-1}^{*, n o r m} S_{t-1}^{\frac{\nu}{2}-1}}{\Pi_{F, t}^{*}}+G_{t}^{*}-\tau_{t}^{*} w_{t}^{*} N_{t}^{*}\right)
$$

${ }^{5}$ Analogously, $D_{t}^{*}$ is per-capita debt of the foreign government; $D_{t}^{*, N o r m}=\frac{D_{t}^{*} R_{t}^{*}}{P_{t}^{*}}$ and $w_{t}^{*}=\frac{W_{t}^{*}}{P_{F, t}^{*}}$ 
As argued in Ferrero (2009), in principle, a transversality condition holds only for the sum of the debts. This is due to the fact that there might exist equilibria in which one government lends infinitely to agents, the other government borrows infinitely from agents, but households' natural debt limit equations are never violated because of non-state contingent asset trading. As we will look to equilibria around a symmetric steady state, we will not fall into these cases. The transversality condition is:

$$
\lim _{T \rightarrow \infty} \mathbb{E}_{t}\left\{Q_{t, T}\left[D_{T}+\phi_{T} D_{T}^{*}\right]\right\}=0
$$

Government spending is exogenous for each country and follows an $\operatorname{AR}(1)$ :

$$
\begin{aligned}
& \ln \left(G_{t}\right)=\rho_{g} \ln \left(G_{t-1}\right)+\left(1-\rho_{g}\right) \ln (\bar{G}) \\
& \ln \left(G_{t}^{*}\right)=\rho_{g}^{*} \ln \left(G_{t-1}^{*}\right)+\left(1-\rho_{g}^{*}\right) \ln \left(\bar{G}^{*}\right)
\end{aligned}
$$

Where $\bar{G}, \bar{G}^{*}$ denote, respectively, home and foreign steady-state government spending. We show, later, that modelling government spending in the utility function allows us to endogenously get the value of government-spending-toGDP ratio at steady-state. Also it enriches the model for further extensions and exercises such as the study of optimal government spending.

\section{5}

\section{Market Clearing}

For the market clearing we have that:

$$
\begin{aligned}
Y_{t}(i) & =C_{H, t}(i)+C_{H, t}^{*}(i)+g_{t}(i) \Longleftrightarrow \\
\Longleftrightarrow Y_{t}(i) & =\left(\frac{P_{H, t}(i)}{P_{H, t}}\right)^{-\theta}\left(\frac{\nu}{2} \frac{P_{t}}{P_{H, t}} C_{t}+\left(1-\frac{\nu}{2}\right) \frac{\phi_{t} P_{t}^{*}}{P_{H, t}} C_{t}^{*}+G_{t}\right)
\end{aligned}
$$

which implies that:

$$
Y_{t}=\frac{\nu}{2} \frac{P_{t}}{P_{H, t}} C_{t}+\left(1-\frac{\nu}{2}\right) \frac{\phi_{t} P_{t}^{*}}{P_{H, t}} C_{t}^{*}+G_{t}
$$

and for the foreign economy:

$$
Y_{t}^{*}=\left(1-\frac{\nu}{2}\right) \frac{P_{t}}{\phi_{t} P_{F, t}^{*}} C_{t}+\frac{\nu^{*}}{2} \frac{P_{t}^{*}}{P_{F, t}^{*}} C_{t}^{*}+G_{t}^{*}
$$

Also, bonds market clearing implies:

$$
\begin{aligned}
& B_{H, t}+\phi_{t} B_{H, t}^{*}=R_{t-1} D_{t-1} \\
& B_{F, t}+\phi_{t} B_{F, t}^{*}=R_{t-1}^{*} D_{t-1}^{*}
\end{aligned}
$$




\section{6}

\section{Equilibrium}

An equilibrium in the world economy with positive nominal interest rates may be described by:

- Agents and firms optmization equations;

- governments budget constraints;

- market clearing equations;

- government policies and interest rate rules for both countries;

- initial conditions for the endogenous variables.

A mathematical representation of the equilibrium with the set of equations and variables is presented in Appendix B. Next we present the social-planner's problem and compute the efficient steady state equations.

\section{7}

\section{Social-Planner's Problem}

The social-planner's problem is characterized by:

$$
\begin{array}{cl}
\max _{C_{t}, C_{t}^{*}, N_{t}, N_{t}^{*}} & \frac{1}{2}\left(U\left(C_{t}\right)-V\left(N_{t}\right)+J\left(G_{t}\right)+U\left(C_{t}^{*}\right)-V\left(N_{t}^{*}\right)+J\left(G_{t}^{*}\right)\right) \\
G_{t}, G_{t}^{*}, S_{t} & \\
& A_{t} N_{t}=\frac{\nu}{2} S_{t}^{1-\frac{\nu}{2}} C_{t}+\left(1-\frac{\nu}{2}\right) S_{t}^{\frac{\nu}{2}} C_{t}^{*}+G_{t}(12) \\
& A_{t}^{*} N_{t}^{*}=\left(1-\frac{\nu}{2}\right) \tilde{S}_{t}^{-\frac{\nu}{2}} C_{t}+\frac{\nu}{2} S_{t}^{-\left(1-\frac{\nu}{2}\right)} C_{t}^{*}+G_{t}^{*}(13)
\end{array}
$$

FOC's imply:

$$
\begin{aligned}
& U_{c}\left(C_{t}^{*}\right)=U_{c}\left(C_{t}\right) S_{t}^{(\nu-1)} \\
& A_{t}^{*} S_{t} V_{n}\left(N_{t}\right)=A_{t} V_{n}\left(N_{t}^{*}\right) \\
& A_{t} U_{c}\left(C_{t}\right)=V_{n}\left(N_{t}\right) S_{t}^{1-\frac{\nu}{2}} \\
& A_{t}^{*} U_{c}\left(C_{t}^{*}\right)=V_{n}\left(N_{t}^{*}\right) S_{t}^{\frac{\nu}{2}-1} \\
& V_{n}\left(N_{t}^{*}\right)=A_{t}^{*} J_{g}\left(G_{t}^{*}\right) \\
& V_{n}\left(N_{t}\right)=A_{t} J_{g}\left(G_{t}\right)
\end{aligned}
$$

So in a symmetric steady state, with $\bar{S}=1$ and $\bar{A}=\bar{A}^{*}=1$ we have:

$$
\begin{aligned}
& \bar{C}=\bar{C}^{*} \quad \bar{N}=\bar{N}^{*} \quad \bar{G}=\bar{G}^{*} \\
& V_{n}(\bar{N})=J_{g}(\bar{G})=U_{c}(\bar{C})
\end{aligned}
$$


The social-planner steady-state does not define the level of public debt. ${ }^{6}$ In fact there is a continuum of steady-states depending on the level of this variable. For our calculations we set steady-state government debt to zero, for both countries, in order to solve this indeterminacy. ${ }^{7}$ In Appendix D we show that with the use of the subsidy $\chi$ the social-planner steady-state with zero government debt is achievable in a decentralized economy.

${ }^{6}$ Note that the social-planner optimal conditions depend only in time-t variables, that's why we can state its problem as a period-by-period maximization.

${ }^{7}$ See for example Lucas and Stokey (1983) or Motta and Rossi (2013) 


\section{3}

\section{Specifications and Implementation}

In this section we explain all the specifications as well as computation methods we used. First we define the calibration of each parameter of the economy; then we define simple rules for monetary and fiscal policy; finally we explain the welfare measures used to compute our welfare-ranking.

\section{1}

\section{Calibration}

Our model resembles Schmitt-Grohé and Uribe (2006) in the way we perform the simple rules analysis and Cook and Devereux (2013) in the way we model the households and firms. ${ }^{1}$ To calibrate the model we rely basically on these works and Schmitt-Grohe and Uribe (2004). So, as in Cook and Devereux (2013), we set the main parameters to standard values: the discount factor, $\beta$, is set to .99; the intermediate goods elasticity, $\theta$, equals 5 ; the inverse Frisch elasticity, $\sigma_{n}$, is 1 ; the intertemporal elasticity of substitution, $\sigma_{c}$, equals 2 ; the probability of not-adjusting prices, $\kappa$, is .85; and the home bias parameter, $\nu$, equals 1 . For the specifications defined in the next subsection: the smooth parameter of the monetary and fiscal rules, respectively $\left\{\rho_{r}, \rho_{r}^{*}\right\}$ and $\left\{\rho_{\tau}, \rho_{\tau}^{*}\right\}$, are 0.7 , as standard in literature, to account for inertia in these types of rules; ${ }^{2}$ the smooth parameters of exogenous $A R(1)$ of government spending, $\left\{\rho_{g}, \rho_{g}^{*}\right\}$, are .87 and of the productivity shock, $\left\{\rho_{a}, \rho_{a}^{*}\right\}$ are .8556 ; also the standard deviations of productivity shocks, $\epsilon_{a}, \epsilon_{a}^{*}$, are 0.0064 all in line with SchmittGrohe and Uribe (2004) and Schmitt-Grohé and Uribe (2006). The response parameters of each rule that will be defined in next subsection vary in a range, such that the optimal values are chosen by our welfare-maximization routine. For the nominal interest rate rules $\left\{\phi_{\pi, h}, \phi_{\pi, f}^{*}, \phi_{\pi, h}^{*}, \phi_{y, h}^{*}, \phi_{y, f}^{*}, \phi_{y, h}, \phi_{\pi, f}, \phi_{y, f}\right\}$ range in $[0,3]$. The ranges are in line with Schmitt-Grohé and Uribe (2006) and such that it is economically realistic for a monetary authority to respond within them. Finally, taxes response to deviations of the debt-to-output ratio

\footnotetext{
${ }^{1}$ Cook and Devereux (2013) design an open economy with consumption home bias, countries with same size and government spending in the utility function. Despite their modelling being similar to ours and useful in our context, their paper is focused on the zero lowerbound constraint, a feature that may be of further investigation. Differently from us, they use only lump-sum taxes.

${ }^{2}$ See for example Parrado and Velasco (2002)
} 
from steady-state, denoted by $\gamma_{\tau}, \gamma_{\tau}^{*}$, varies in $[0.01,0.51]$ to induce a stable equilibrium. ${ }^{3}$ Table 3.1 summarizes the calibration:

Table 3.1: Summary of Parameters Calibration

\begin{tabular}{|l|l|l|}
\hline Parameter & Calibration & Definition \\
\hline$\beta$ & 0.99 & Discount Factor \\
\hline$\theta$ & 5 & Intermediate Goods Elasticity \\
\hline$\sigma_{n}$ & 1 & Inverse Frisch Elasticity \\
\hline$\sigma_{c}$ & 2 & Intertemporal Elasticity of Substitution \\
\hline$\kappa$ & 0.85 & Probability of not-resetting prices \\
\hline$\nu$ & 1 & Degree of Openness \\
\hline$\rho_{r}, \rho_{r}^{*}$ & 0.7 & Monetary Policy Smooth Parameter \\
\hline$\rho_{\tau}, \rho_{\tau}^{*}$ & 0.7 & Fiscal Policy Smooth Parameter \\
\hline$\rho_{g}, \rho_{g}^{*}$ & .87 & Government Spending AR(1) Smooth Parameter \\
\hline$\rho_{a}, \rho_{a}^{*}$ & .8556 & Productivity Shock AR(1) Smooth Parameter \\
\hline$\epsilon_{a}, \epsilon_{a}^{*}$ & 0.0064 & Productivity Shock Standard Deviation \\
\hline$\phi_{\pi, h}, \phi_{y, h}, \phi_{\pi, f}, \phi_{y, f}$ & {$[0,3]$} & Monetary Policy Parameter \\
\hline$\phi_{\pi, f}^{*}, \phi_{y, f}^{*}, \phi_{\pi, h}^{*}, \phi_{y, h}^{*}$ & {$[0,3]$} & Monetary Policy Parameter \\
\hline$\gamma_{\tau}, \gamma_{\tau}^{*}$ & {$[0.01,0.51]$} & Fiscal Policy Parameter \\
\hline
\end{tabular}

\section{2}

\section{Monetary and Fiscal Policy Rules}

To complete the model presented in the previous section we define rules for home and foreign nominal interest rate and income-tax. For the monetary policy we define two specifications.

Specification I:

$$
\begin{aligned}
\frac{R_{t}}{\bar{R}} & =\left(\frac{R_{t-1}}{\bar{R}}\right)^{\rho_{r}}\left(\left(\Pi_{H, t}\right)^{\phi_{\pi, h}}\left(\frac{Y_{t}}{\bar{Y}}\right)^{\phi_{y, h}}\right)^{1-\rho_{r}} \\
\frac{R_{t}^{*}}{\bar{R}^{*}} & =\left(\frac{R_{t-1}^{*}}{\bar{R}^{*}}\right)^{\rho_{r}^{*}}\left(\left(\Pi_{F, t}^{*}\right)^{\phi_{\pi, f}^{*}}\left(\frac{Y_{t}^{*}}{\bar{Y}^{*}}\right)^{\phi_{y, f}^{*}}\right)^{1-\rho_{r}^{*}}
\end{aligned}
$$

Where the optimized parameters are $\phi_{\pi, h}, \phi_{y, h}, \phi_{\pi, f}^{*} \phi_{y, f}^{*}$. In this case the monetary authority only responds to its own endogenous variables. This specification is run under cooperation and non-cooperation of the policy authorities.

${ }^{3}$ We don't allow $\gamma_{\tau}=\gamma_{\tau}^{*} \leq 0$ because despite mathematically possible an open-economy equilibrium with only one exogenous tax, i.e. $\left\{\gamma_{\tau}=0 \underline{\vee} \gamma_{\tau}^{*}=0\right\}$ (considering combinations of the other parameters), it would not be possible in a closed economy, i.e. we must have endogenous income-tax in a closed economy for existence of equilibria. Also we don't allow for negative values of $\left\{\gamma_{\tau}, \gamma_{\tau}^{*}\right\}$ following Schmitt-Grohé and Uribe (2006). 
Specification II:

$$
\begin{aligned}
& \frac{R_{t}}{\bar{R}}=\left(\frac{R_{t-1}}{\bar{R}}\right)^{\rho_{r}}\left(\left(\Pi_{H, t}\right)^{\phi_{\pi, h}}\left(\Pi_{F, t}^{*}\right)^{\phi_{\pi, f}}\left(\frac{Y_{t}}{\bar{Y}}\right)^{\phi_{y, h}}\left(\frac{Y_{t}^{*}}{\bar{Y}^{*}}\right)^{\phi_{y, f}}\right)^{1-\rho_{r}} \\
& \frac{R_{t}^{*}}{\bar{R}^{*}}=\left(\frac{R_{t-1}^{*}}{\bar{R}^{*}}\right)^{\rho_{r}^{*}}\left(\left(\Pi_{F, t}^{*}\right)^{\phi_{\pi, f}^{*}}\left(\Pi_{H, t}\right)^{\phi_{\pi, h}^{*}}\left(\frac{Y_{t}^{*}}{\bar{Y}^{*}}\right)^{\phi_{y, f}^{*}}\left(\frac{Y_{t}}{\bar{Y}}\right)^{\phi_{y, h}^{*}}\right)^{1-\rho_{r}^{*}}
\end{aligned}
$$

Where the optimized parameters are $\phi_{\pi, h}, \phi_{\pi, f}, \phi_{y, h}, \phi_{y, f}^{*}, \phi_{\pi, f}^{*}, \phi_{\pi, h}^{*}, \phi_{y, f}^{*}$, $\phi_{y, h}^{*}$. In this case the monetary authority also responds to the other country's endogenous variables. This specification is run under cooperation of the policy authorities. Rules (3-1)-(3-4) are based on Schmitt-Grohé and Uribe (2006), expanding their choices for an open economy context. Our intent is to isolate an endogenous cooperation factor, measuring to what extent it is good to respond to the other country's variables from a welfare perspective. For the income-tax we define:

$$
\begin{aligned}
& \tau_{t}=\rho_{\tau} \tau_{t-1}+\left(1-\rho_{\tau}\right) \bar{\tau}+\left(1-\rho_{\tau}\right) \gamma_{\tau}\left(\frac{D_{t}}{Y_{t}}-\frac{\bar{D}}{\bar{Y}}\right) \\
& \tau_{t}^{*}=\rho_{\tau}^{*} \tau_{t-1}^{*}+\left(1-\rho_{\tau}^{*}\right) \bar{\tau}^{*}+\left(1-\rho_{\tau}^{*}\right) \gamma_{\tau}^{*}\left(\frac{D_{t}^{*}}{Y_{t}^{*}}-\frac{\bar{D}^{*}}{\bar{Y}^{*}}\right)
\end{aligned}
$$

Where the optimized parameters are $\gamma_{\tau}, \gamma_{\tau}^{*} \cdot{ }^{4}$ Deviations from steady-state are chosen because this represents policies that require few information of the policy-maker in order to be implemented.

\section{3}

\section{Welfare Measures}

To perform the welfare-ranking of the different prescriptions and the Ramsey-policy we define the welfare measures. First we define the utility function of the home and foreign agents, respectively: ${ }^{5}$

$$
\begin{aligned}
\mathcal{U}_{t} & =\frac{C_{t}^{1-\sigma_{c}}}{1-\sigma_{c}}+\frac{G_{t}^{1-\sigma_{c}}}{1-\sigma_{c}}-\frac{N_{t}^{1+\sigma_{n}}}{1+\sigma_{n}} \\
\mathcal{U}_{t}^{*} & =\frac{\left(C_{t}^{*}\right)^{1-\sigma_{c}}}{1-\sigma_{c}}+\frac{\left(G_{t}^{*}\right)^{1-\sigma_{c}}}{1-\sigma_{c}}-\frac{\left(N_{t}^{*}\right)^{1+\sigma_{n}}}{1+\sigma_{n}}
\end{aligned}
$$

Under cooperation the monetary and fiscal authorities of both countries maximize the average of the discounted utility of each country's representative

${ }^{4}$ We choose not to optimize $\rho_{r}, \rho_{r}^{*}, \rho_{\tau}, \rho_{\tau}^{*}$. In fact, there is evidence for inertia in these rules, and in all our tests we find interior solution for most of the optimized parameters, that are multiplied by these smooth parameters, so we could get rid of the multiplicative effect.

${ }^{5}$ For simplicity we assume that $\sigma_{g}=-G \frac{J_{g g}(G)}{J_{g}(G)}=-C \frac{U_{c c}(C)}{U_{c}(C)}=\sigma_{c}$ as inCook and Devereux (2013). 
agent, that is the cooperative welfare:

$$
\mathcal{W}_{c}=\frac{1}{2} \mathbb{E}_{0}\left\{\sum_{t=0}^{\infty} \beta^{t}\left(\mathcal{U}_{t}+\mathcal{U}_{t}^{*}\right)\right\}
$$

Equation (3-9) states that the cooperative welfare is a function of $\left\{C, G, N, C^{*}, N^{*}, G^{*}\right\}$, i.e. $\mathcal{W}_{c}\left(C, G, N, C^{*}, N^{*}, G^{*}\right)$. Under non-cooperation each country maximizes its own welfare, defined for home and foreign country, respectively, by:

$$
\begin{aligned}
& \mathcal{W}_{n c}^{h}=\mathbb{E}_{0}\left\{\sum_{t=0}^{\infty} \beta^{t} \mathcal{U}_{t}\right\} \\
& \mathcal{W}_{n c}^{f}=\mathbb{E}_{0}\left\{\sum_{t=0}^{\infty} \beta^{t} \mathcal{U}_{t}^{*}\right\}
\end{aligned}
$$

In the same way, equations (3-10) and (3-11) define the home and foreign noncooperative welfare, respectively, as functions of $\{C, N, G\}$ and $\left\{C^{*}, N^{*}, G^{*}\right\}$, i.e. $\mathcal{W}_{n c}^{h}(C, G, N)$ and $\mathcal{W}_{n c}^{f}\left(C^{*}, N^{*}, G^{*}\right)$. Finally we define a measure of welfarecost, $\lambda$, based on Heathcote et al. (2011), that represents the percentage of consumption individuals from home and foreign countries would receive every period to go from the simple-rule equilibrium to the Ramsey-equilibrium. Mathematically, $\lambda$ corresponds to the value that solves:

$$
\mathcal{W}_{s r}\left(\left(1+\frac{\lambda}{100}\right) C, G, N,\left(1+\frac{\lambda}{100}\right) C^{*}, N^{*}, G^{*}\right)=\mathcal{W}_{r m}\left(C, G, N, C^{*}, N^{*}, G^{*}\right)
$$

where $\mathcal{W}_{r m}$ is the conditional welfare of the Ramsey-economy and $\mathcal{W}_{s r}$ is the welfare under simple rules.

\section{4}

\section{Implementation}

To implement the welfare-ranking we performed three exercises. All routines are based on the non-linear definition of the model. ${ }^{6}$ The first exercise is to solve the Ramsey-Problem, mathematically defined in Appendix C, and the output is the conditional welfare, i.e. the welfare conditional on the initial period - including the lagrange multipliers - being the steady-state of the economy. The Ramsey steady-state is such that home and foreign debt, $\left\{D, D^{*}\right\}$, equal zero, home and foreign inflation, $\Pi_{H}, \Pi_{F}^{*}$, equal one and the nominal interest rates, $R, R^{*}$ equal $1 / \beta$. We calculate the optimal steady-state and plot the IRFs after the productivity shock. ${ }^{7}$

In exercise two we run a grid-search for specifications I and II and

\footnotetext{
${ }^{6}$ In fact, we rely on the second-order approximation of Dynare Software when needed.

${ }^{7}$ In Appendix $\mathrm{C}$ we also give a hint on how to analytically calculate the Ramsey steadystate.
} 
find the values of the parameters in each rule that maximize a second-order approximation of (3-9), the conditional cooperative welfare. For that we write the non-linear model as defined in Appendix B and rely on a second-order approximation around the Ramsey steady-state - which is achievable in a decentralized economy -. This is the cooperative exercise.

For exercise three we use rules (3-1), (3-2), (3-5) and (3-6) to complete the economy and run the following steps:

1. Given values for the foreign parameters in rules (3-2) and (3-6) find the values of the parameters in (3-1) and (3-5) that maximize a second-order approximation of (3-10);

2. calculate a second-order approximation of (3-9) and compare with the previous value of (3-9). If the change is lower than our threshold, stop, otherwise go to step $3 ;^{8}$

3. using the values found for (3-1) and (3-5) at step 1 find the values of the parameters in (3-2) and (3-6) that maximize a second-order approximation of (3-11);

4. calculate a second-order approximation of (3-9) and compare with the previous value of (3-9). If the change is lower than our threshold, stop, otherwise go to step 1.

That is, we find the Nash Equilibrium of policy spectrum where one country implements the best response given the policy of the other country. This is the non-cooperative exercise. For the first round of this routine we set initial values for each welfare and parameters. The optimal values of the parameters are found by a grid-search routine and results are shown in next section.

Finally we designed a routine to numerically find the equivalentconsumption associated with the outputs of exercises 2 and 3 with respect to exercise 1. For that we use:

$\mathcal{W}_{s r}(\lambda)=\frac{\left(\left(1+\frac{\lambda}{100}\right) C_{t}\right)^{1-\sigma_{c}}}{1-\sigma_{c}}+\frac{G_{t}^{1-\sigma_{c}}}{1-\sigma_{c}}-\frac{N_{t}^{1+\sigma_{n}}}{1+\sigma_{n}}+\frac{\left(\left(1+\frac{\lambda}{100}\right) C_{t}^{*}\right)^{1-\sigma_{c}}}{1-\sigma_{c}}+\frac{\left(G_{t}^{*}\right)^{1-\sigma_{c}}}{1-\sigma_{c}}-\frac{\left(N_{t}^{*}\right)^{1+\sigma_{n}}}{1+\sigma_{n}}$ and, using the optimal values of the parameters in exercise 2 and 3, find the value of $\lambda$ that satisfies equation (3-12).

\footnotetext{
${ }^{8}$ If we used the average of the second order approximations of (3-10) and (3-11) we would be prone to mistakenly calculate the average welfare of the economy due to approximation issues.
} 


\section{Results}

To generate we ran stochastic simulations where the economy starts in the steady-state and then is hit by a home-country productivity shock. ${ }^{1}$

\section{1}

\section{Ramsey-problem}

For the Ramsey-problem instruments are: home and foreign nominal interest rate, $R, R^{*}$, and income-tax, $\tau, \tau^{*}$. Figures (4.1) and (4.2) show the IRFs after a period-0 home productivity shock.
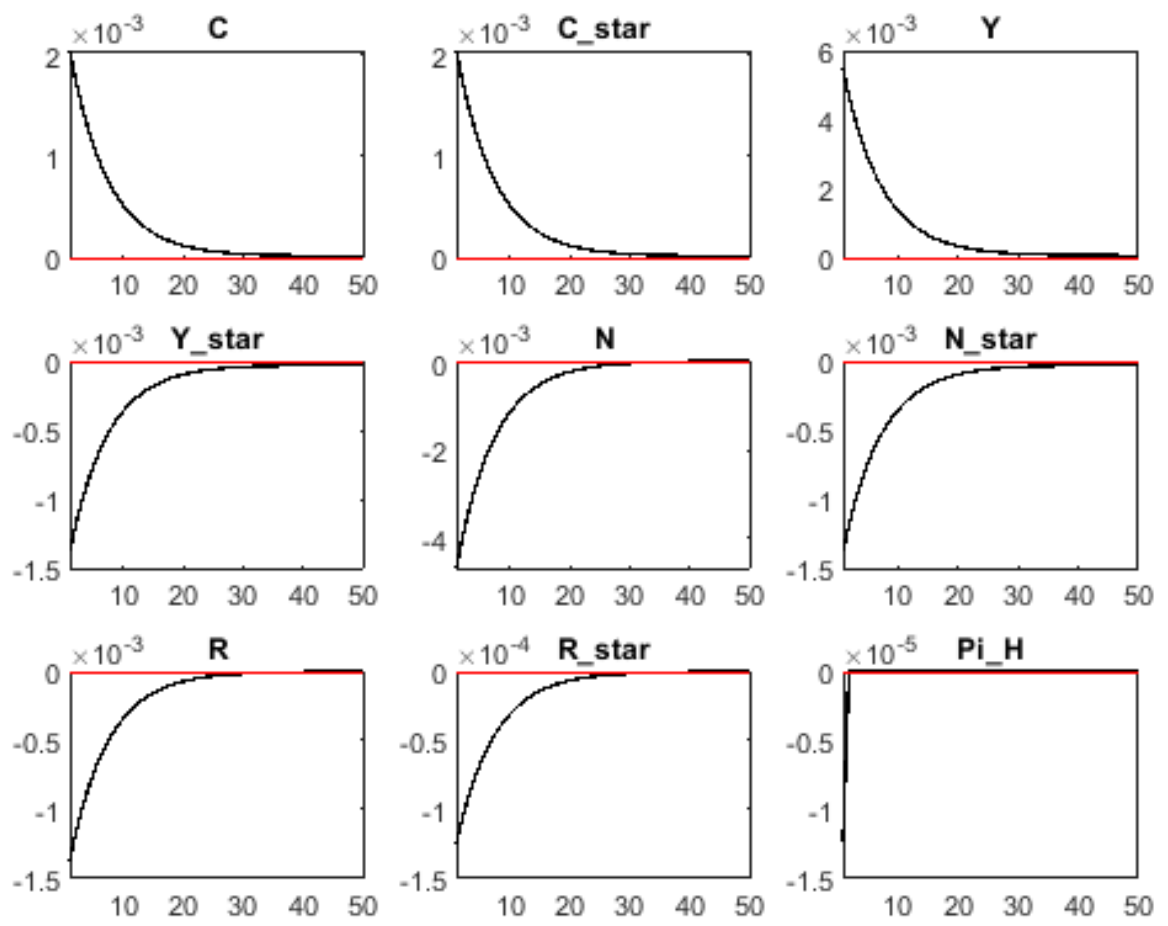

Figure 4.1: Ramsey-problem IRFs

A positive productivity shock lowers firms marginal costs creating a deflationary pressure in the home country, rise in aggregate demand and

${ }^{1}$ Therefore we set the foreign-country productivity shock to 0 , i.e. $A_{t}^{*}=1 \forall t$. As discussed, for example, in Beetsma and Jensen (2005) and Cook and Devereux (2013), macroeconomic responses are dependent on the relative shocks of the two countries, so there is no loss of generality. 

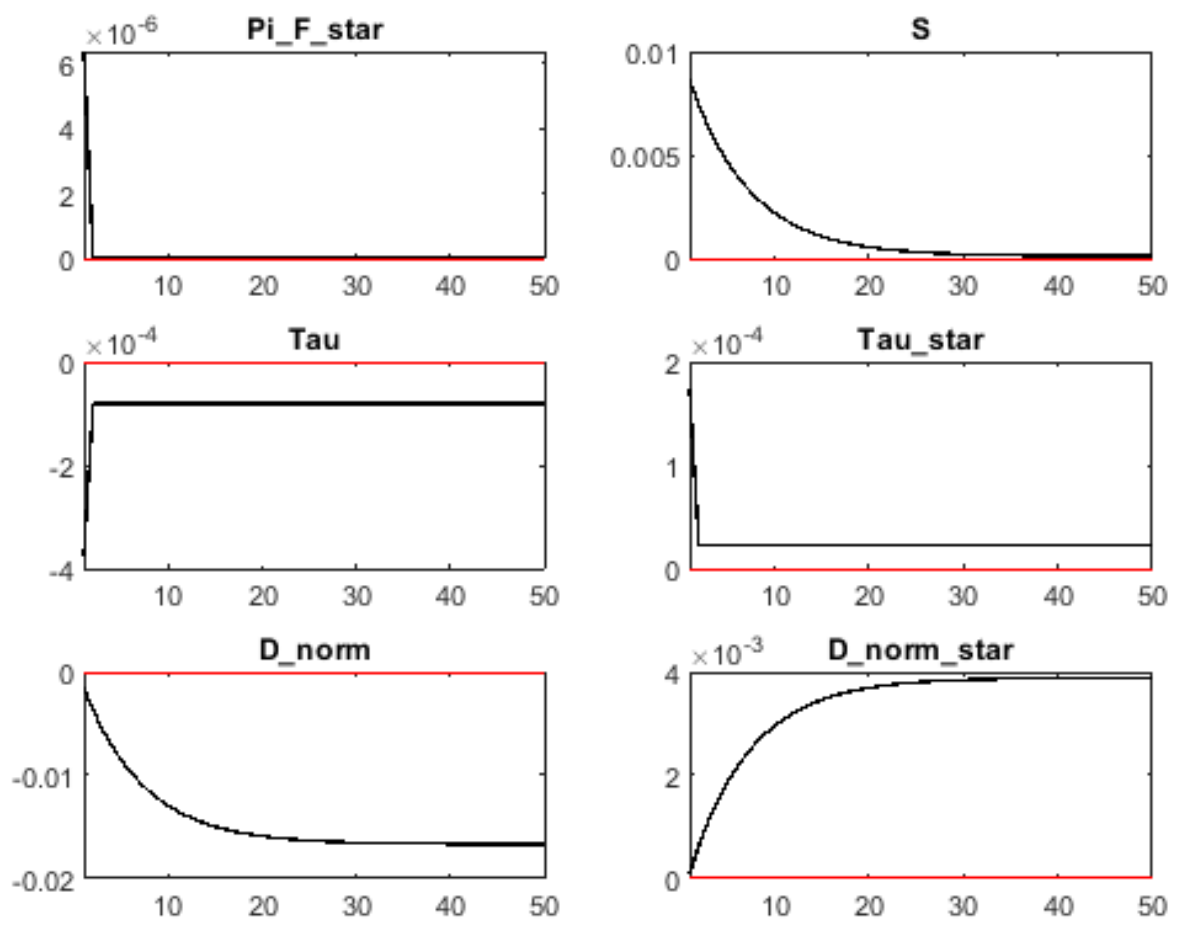

Figure 4.2: Ramsey-problem IRFs

output growth. Within the open economy environment there is a secondary impact, on the home terms of trade, that depreciates, channelling demand of foreign and home consumption into the home country. This effect induces a fall in foreign-goods demand, generating foreign deflation, as well as labour demand and output drop. In the optimal response, interest rate of both countries lower, counteracting the deflationary pressures. ${ }^{2}$ Consumption is equated across countries due to optimal risk sharing and hours on home country lowers due to substitution effect.

In what pertains the distortionary taxation, we see that in the home country there is a fall in the income-tax and a one-period deflation; in the foreign country taxes rise and there is one-period inflation. In what pertains inflation movements, literature argues that this aggregate acts as a shock absorber, but as it is costly in a sticky-price model, the main burden of adjustment is done via taxation. ${ }^{3}$ The fall in home inflation and rise in foreign inflation channel more demand into home goods; also the fall in home tax and rise in foreign tax have the same effect, depreciating even more the terms of trade. In fact, the mechanism is that a fall in home income-tax rises the supply of labour and lowers the real wage, inducing a home deflationary pressure and

${ }^{2}$ If we considered lump-sum taxation, indeed, it would be possible to keep inflation at its steady-state.

${ }^{3}$ See for example Siu (2004). 
depreciating the home terms of trade. ${ }^{4}$ Debt in both countries adjust so as to keep the budget constraint equation holding. In fact, to understand how dynamics are changed by the distortionary taxation, compared to a lump-sum taxes case, the more accentuated depreciation of the terms of trade caused by tax and inflation movements channels even more demand to home country goods, worsening the recession in foreign country -lowering foreign output and hours worked -; but raising more than proportionately home output, home (and foreign) consumption, and hours worked (this last one falling less than in the lump-sum case). Now back to distortionary tax scenarios, this combination of tax responses leads to a cooperative welfare that is higher than if foreign country tried to channel demand to its goods. As in cited open economy works, we also find permanent deviations from steady-state for taxes, output, debt and the terms of trade. Indeed, as taxes have distortion effects, the best option is for them to face a jump and then become constant.

Our findings might seem in contrast with Benigno and De Paoli (2006) that argues that after a positive supply shock it would be optimal to raise home income-taxes. They find that it would induce a terms of trade appreciation, channelling more demand into the foreign country, thus lowering home domestic disutility of production without a decline in home utility of consumption. The difference arises because they work with a small open economy, thus a home supply shock has no effect on foreign variables. ${ }^{5}$ When we work with countries with same size and a measure of cooperative welfare, foreign economy dynamics must be taken into account leading to the effects above mentioned.

To confirm our findings we perform an exercise where we solve the Ramsey-problem considering welfare to be (3-11), i.e. only foreign country welfare, first with lump-sum taxation (instruments being home and foreign nominal interest rate only), and then with income-taxation. The result is that after a home positive technology shock the terms of trade is more appreciated in the case of distortionary taxation then in the lump-sum case, accounting for the terms of trade externality as exposed in Benigno and De Paoli (2006), where now both countries use taxation to enhance demand for foreign country goods. ${ }^{6}$

\section{2}

\section{Simple Rules}

Table 4.1 shows the results for Specifications I and II:

\footnotetext{
${ }^{4}$ The mechanism is analogous for the foreign economy.

${ }^{5}$ Additionally, their welfare measure is only home country.

${ }^{6}$ The terms of trade externality is the exploitation or managing of the terms of trade, by a country, to enhance welfare.
} 
Table 4.1: Results of different specifications

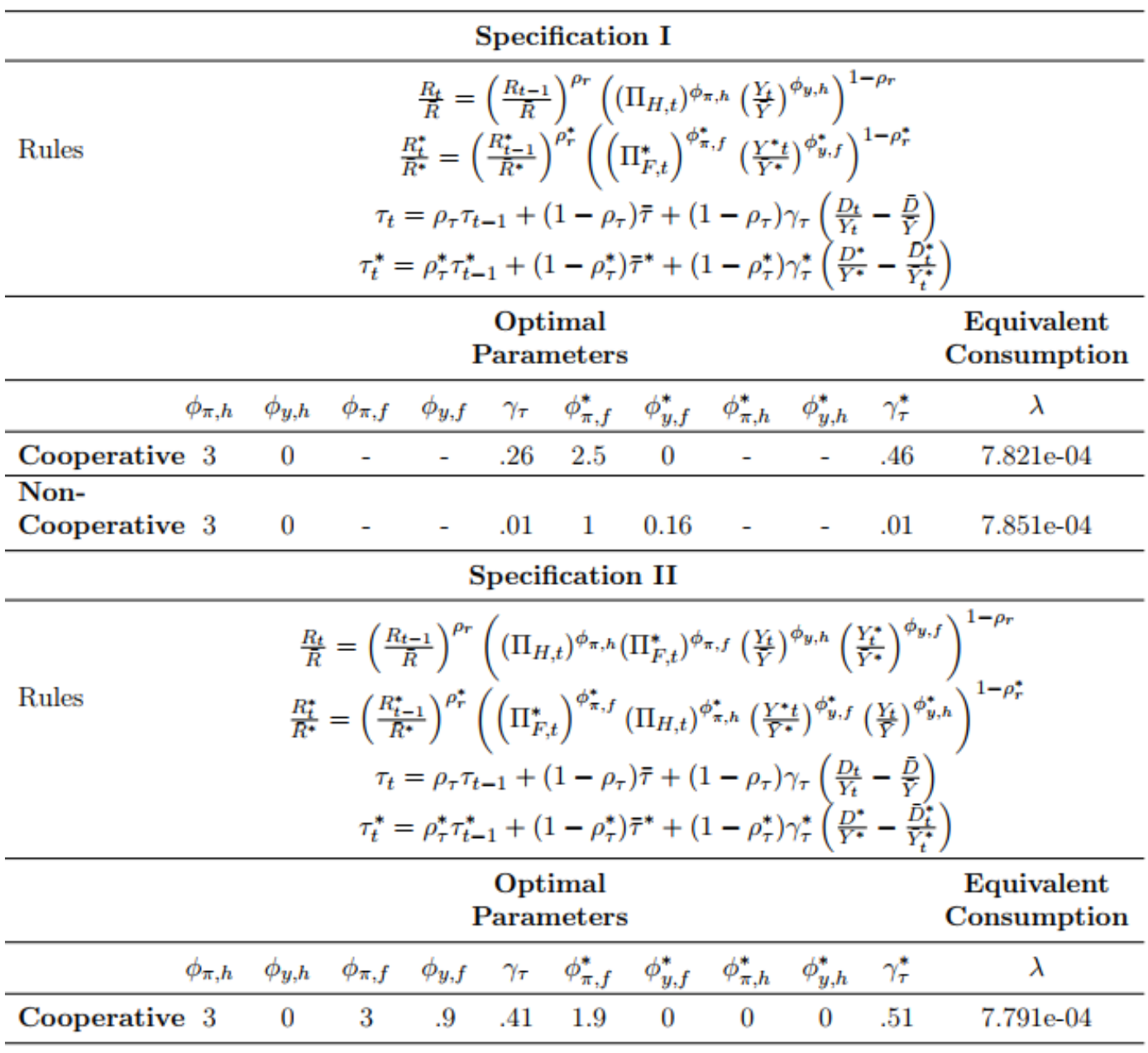

Notice that the closer to zero the equivalent consumption, the closer is the simple-rule equilibrium welfare to the Ramsey-economy welfare. Therefore, specification II yields the highest welfare, where cooperative welfare is maximized and home monetary authorities respond to foreign country endogenous variables. The non-cooperative case yields the lowest welfare of the exercises. All rules approximate well, in a welfare-sense, the Ramsey-equilibrium. In all cases home own-inflation response parameter is at the upper bound of the grid. This might be due to an inflation-stabilization bias, as our economy is cashless. ${ }^{7}$ Also home country never responds to own-country output-gap. This is common in the literature after supply shocks, as, for home country, output and inflation move in opposite directions creating an stabilization trade-off. Notice that this effect is not present in the foreign country, so the home supply shock has a similar effect, on output and inflation, to a demand shock for foreign country, channelling demand from foreign to home goods and mov-

${ }^{7}$ See for example Schmitt-Grohé and Uribe (2006) that find the same in the closed economy case. 
ing these two aggregates in the same direction. Also when in Specification II home country responds to foreign output-gap after hitting the upperbound of foreign inflation response. Indeed if we allow for higher values of home and foreign inflation, home responses to foreign output-gap decrease and welfare is improved, meaning that it is second-best to respond to output with respect to inflation. For the foreign country zero output response occurs in the cooperative cases. In fact, results show that it is better for foreign country to respond to own-inflation and more aggressively to taxes in a cooperative case, managing the terms of trade; in the non-cooperative case foreign country is more worried with its output decrease and relies the least possible on distortionary taxation. ${ }^{8}$

To further explain our results of simple rules we present in Figures (4.3) and (4.4) the IRFs of Specification I, cooperative case. The simple-rules economy mimics the Ramsey-economy for most variables. For taxes notice that in the initial periods their levels rise, falling afterwards. This is due to the type of rule we set, that forces taxes to vary in the same direction of debt (remember that $\left\{\gamma_{\tau}, \gamma_{\tau}^{*}\right\}>0$ ). As hours worked falls in both countries, despite a rise in real wages, debt rises in the short-run, forcing taxes also to rise. ${ }^{9}$ Notice, notwithstanding, that for the most part of the transition (approximately period 10 onward) taxes behavior as in the Ramsey-economy, reinforcing the mechanisms described. Foreign inflation is also affected by this additional symmetry implied by our rules. ${ }^{10}$

\footnotetext{
${ }^{8}$ In fact $\gamma_{\tau}^{*}$ is in the lowerbound of its grid and $\phi_{\pi, f}^{*}$ is the least in all specifications.

${ }^{9}$ This initial effect implied by the symmetry of the rules might also influence foreign country's decision of relying the least possibly on taxes, seen in Specification I, noncooperative case.

${ }^{10}$ Ferrero (2009) also points symmetry issues associated with simples rules.
} 

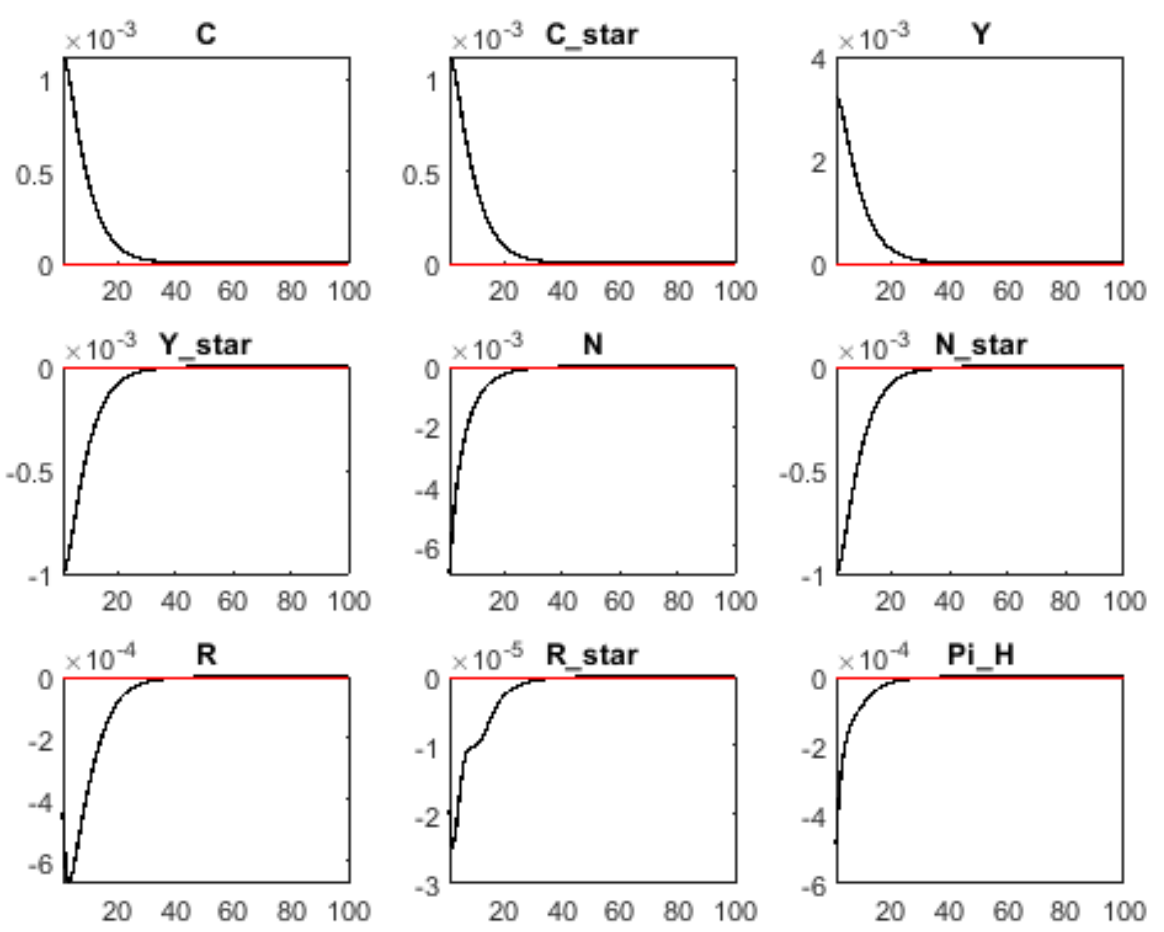

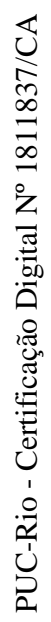

Figure 4.3: Simple Rules IRFs
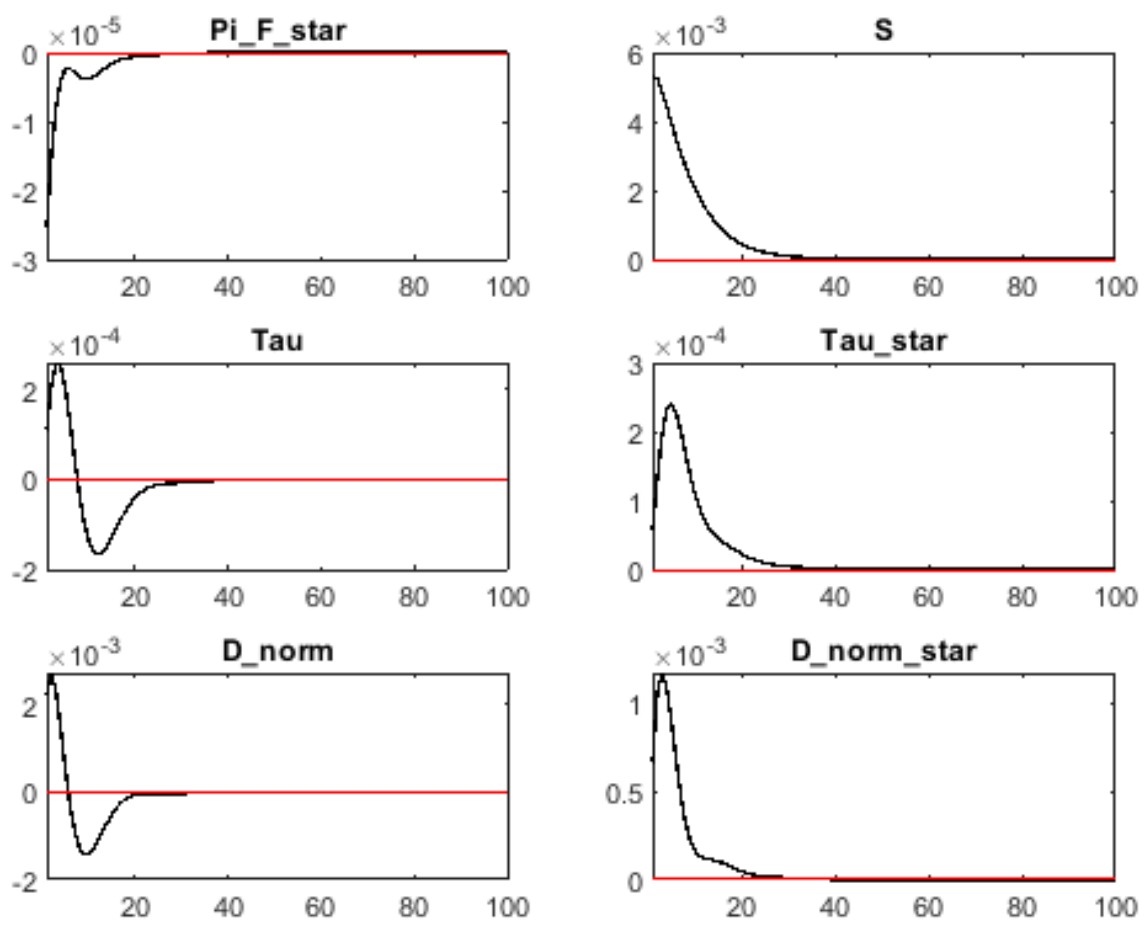

Figure 4.4: Simple Rules IRFs 


\section{5 \\ Conclusion}

In the present paper we develop a two-country open economy New Keynesian model with distortionary taxation and stochastic government spending. After a home productivity shock we analyze the dynamics in a Ramseyequilibrium and in a simple-rules equilibrium. Results for the former equilibrium are that, in a cooperative, symmetric environment, with no home bias, it is optimal to exploit the terms of trade, inducing its depreciation, in order to channel more demand into the home country and thus raising world aggregate welfare. For the latter type of equilibrium we perform a welfare-ranking. Findings are that: it is welfare-enhancing for the world to act cooperatively; home country responds to foreign country inflation-gap and output-gap (the latter as a second-best option); foreign country responds more aggressively with taxes; rules approximate well, in a welfare-sense, the Ramsey-equilibrium; and dynamics with simple-rules are different, for taxes, in the beginning of the cycle, due to symmetry issues, but for the most part, mimic the Ramsey-economy.

To perform this exercises we developed recursive non-cooperative equilibrium calculator, a numerical equivalent-consumption calculator and non-linear models for the simple-rules economy.

For further research it would be interesting to vary the size of each country in a continuum $[0,1]$ and vary the home bias parameter in the range $[1,2]$, to understand how the dynamics are affected by these parameters. Also extensions to the model - as a zero-lowerbound constraint - are possible and would allow for different mechanisms to arise. 


\section{Bibliography}

Aiyagari, R., Marcet, A., Sargent, T. J., and Seppãllã, J. (2002). Optimal taxation without state-contingent debt. Journal of Political Economy, 110(6):1220-1254.

Barro, R. J. (1979). On the determination of the public debt. Journal of Political Economy, 87(5):940-971.

Beetsma, R. M. and Jensen, H. (2005). Monetary and fiscal policy interactions in a micro-founded model of a monetary union. Journal of International Economics, 67:320-352.

Benigno, G. and De Paoli, B. (2006). Optimal fiscal and monetary policy for a small open economy. Mimeo.

Chari, V. V., Christiano, L. J., and Kehoe, P. J. (1991). Optimal fiscal and monetary policy: Some recent results. Journal of Money, Credit and Banking, 23(3):519-539.

Cook, D. and Devereux, M. B. (2013). Sharing the burden: Monetary and fiscal responses to a world liquidity trap. American Economic Journal, 5(3):190-228.

Ferrero, A. (2009). Fiscal and monetary rules for a currency union. Journal of International Economics, 77(1):1-10.

Heathcote, J., Storesletten, K., and Violante, G. (2011). From wages to welfare: Decomposing gains and losses from rising inequality. Advances in Economics and Econometrics: Tenth World Congress, Volume II: Applied Economics, 2:235-280.

Lucas, R. J. and Stokey, N. L. (1983). Optimal fiscal and monetary policy in an economy without capital. Journal of Monetary Economics, 12(1):55-93.

Motta, G. and Rossi, R. (2013). Ramsey monetary and fiscal policy: the role of consumption taxation. (44449031).

Nakajima, T. (2008). Liquidity trap and optimal monetary policy in open economies. Journal of the Japanese and international Economies, 22:1-33.

Parrado, E. and Velasco, A. (2002). Alternative monetary rules in the open economy: A welfare-based approach. 5:295-348. 
Schmitt-Grohe, S. and Uribe, M. (2004). Optimal fiscal and monetary policy under sticky prices. Journal of Economic Theory, 114:198-230.

Schmitt-Grohé, S. and Uribe, M. (2006). Optimal simple and implementable monetary and fiscal rules: Expanded version. (12402).

Siu, H. E. (2004). Optimal fiscal and monetary policy with sticky-prices. Journal of Monetary Economics, 51(6):575-607. 
A

\section{Appendix}

\section{A.1}

\section{Aggregation}

Here we present the aggregating variables, which are standard in open economy context. We define:

$$
\begin{aligned}
C_{H, t} & =\left(\int_{0}^{1} C_{H, t}(i)^{\frac{\theta-1}{\theta}}\right)^{\frac{\theta}{\theta-1}} \\
C_{F, t} & =\left(\int_{0}^{1} C_{F, t}(i)^{\frac{\theta-1}{\theta}}\right)^{\frac{\theta}{\theta-1}}
\end{aligned}
$$

and analogously for the foreign consumption. By solving the optimal consumption aggregation basket:

$$
\begin{array}{ll}
\max _{C_{H, t}(i)} & \left(\int_{0}^{1} C_{H, t}(i)^{\frac{\theta-1}{\theta}} d i\right)^{\frac{\theta}{\theta-1}} \\
\text { s.t. } & \int_{0}^{1} P_{H, t}(i) C_{H, t}(i) d i \leq Z_{t}
\end{array}
$$

we find that

$$
C_{H, t}(i)=\left(\frac{P_{H, t}(i)}{P_{H, t}}\right)^{-\theta} C_{H, t}
$$

with

$$
P_{H, t}=\left(\int_{0}^{1} P_{H, t}(i)^{1-\theta} d i\right)^{\frac{1}{1-\theta}}
$$

such that

$$
\int_{0}^{1} P_{H, t}(i) C_{H, t}(i) d i=P_{H, t} C_{H, t}
$$

and analogously

$$
C_{F, t}(i)=\left(\frac{P_{F, t}(i)}{P_{F, t}}\right)^{-\theta} C_{F, t}
$$

with

$$
P_{F, t}=\left(\int_{0}^{1} P_{F, t}(i)^{1-\theta} d i\right)^{\frac{1}{1-\theta}}
$$


such that

$$
\int_{0}^{1} P_{F, t}(i) C_{F, t}(i) d i=P_{F, t} C_{F, t}
$$

and the analogous with "*" in the variables for the foreign economy. The variable $\theta>1$ is the elasticity of substitution between home (and also foreign) goods. Additionally, by solving:

$$
\begin{aligned}
& \max _{C_{H, t}, C_{F, t}}\left(\frac{C_{H, t}}{\left(\frac{\nu}{2}\right)}\right)^{\frac{\nu}{2}}\left(\frac{C_{F, t}}{1-\frac{\nu}{2}}\right)^{1-\frac{\nu}{2}} \\
& \text { s.t. } \quad P_{H, t} C_{H, t}+P_{F, t} C_{F, t} \leq Z_{t}
\end{aligned}
$$

we find that

$$
\begin{aligned}
C_{H, t} & =\frac{\nu}{2} \frac{P_{t}}{P_{H, t}} C_{t} \\
C_{F, t} & =\left(1-\frac{\nu}{2}\right) \frac{P_{t}}{P_{F, t}} C_{t}
\end{aligned}
$$

and the analogous for the foreign economy:

$$
\begin{aligned}
C_{H, t}^{*} & =\left(1-\frac{\nu}{2}\right) \frac{P_{t}^{*}}{P_{H, t}^{*}} C_{t}^{*} \\
C_{F, t}^{*} & =\frac{\nu}{2} \frac{P_{t}^{*}}{P_{F, t}^{*}} C_{t}^{*}
\end{aligned}
$$

The government solves the maximization problem:

$$
\begin{array}{ll}
\max _{g_{t}(i)} & \left(\int_{0}^{1} g_{t}(i)^{\frac{\theta-1}{\theta}} d i\right)^{\frac{\theta}{\theta-1}} \\
\text { s.t. } & \int_{0}^{1} P_{H, t}(i) g_{t}(i) d i \leq Z_{t}
\end{array}
$$

which gives:

$$
g_{t}(i)=\left(\frac{P_{H, t}(i)}{P_{H, t}}\right)^{-\theta} G_{t}
$$

and for the foreign economy:

$$
g_{t}^{*}(i)=\left(\frac{P_{F, t}^{*}(i)}{P_{F, t}^{*}}\right)^{-\theta} G_{t}^{*}
$$




\section{A.2}

\section{Equilibrium}

The equilibrium in this economy is defined by the equations below. We state the equations in terms of real aggregates whenever possible, so we don't have prices anywhere. For the price-setting part we define auxiliary variables to be able to write recursively our non-linear equations. We divide the equilibrium into Price-setting equations:

$$
\begin{aligned}
& \Pi_{H, t}^{1-\theta}=(1-\kappa) \tilde{\Pi}_{H, t}^{1-\theta}+\kappa \\
& X_{1, t}=C_{t}^{-\sigma_{c}} Y_{t} S_{t}^{\frac{\nu}{2}-1} \frac{w_{t}}{A_{t}}+\kappa \beta \Pi_{H, t+1}^{\theta} X_{1, t+1} \\
& X_{2, t}=C_{t}^{-\sigma_{c}} Y_{t} S_{t}^{\frac{\nu}{2}-1}+\kappa \beta \Pi_{H, t+1}^{\theta-1} X_{2, t+1} \\
& \tilde{\Pi}_{H, t}=\frac{\theta}{\theta-1}(1-\chi) \Pi_{H, t} \frac{X_{1, t}}{X_{2, t}} \\
& \left(\Pi_{F, t}^{*}\right)^{1-\theta}=(1-\kappa)\left(\tilde{\Pi}_{F, t}^{*}\right)^{1-\theta}+\kappa \\
& \left.X_{1, t}^{*}=\left(C_{t}^{*}\right)^{-\sigma_{c}} Y_{t}^{*} S_{t}^{1-\frac{\nu}{2}} \frac{w_{t}^{*}}{A_{t}^{*}}+\kappa \beta\left(\Pi_{F, t+1}^{*}\right)^{\theta}\right) X_{1, t+1}^{*} \\
& X_{2, t}^{*}=\left(C_{t}^{*}\right)^{-\sigma_{c}} Y_{t}^{*} S_{t}^{1-\frac{\nu}{2}}+\kappa \beta\left(\Pi_{F, t+1}^{*}\right)^{\theta-1} X_{2, t+1}^{*} \\
& \tilde{\Pi}_{F, t}^{*}=\frac{\theta}{\theta-1}(1-\chi) \Pi_{F, t}^{*} \frac{X_{1, t}^{*}}{X_{2, t}^{*}}
\end{aligned}
$$

where $\Pi_{H, t}=P_{H, t} / P_{H, t-1} ; \Pi_{F, t}^{*}=P_{F, t}^{*} / P_{F, t-1}^{*} ; \tilde{\Pi}_{H, t}=\tilde{P}_{H, t} / \tilde{P}_{H, t-1} ; \tilde{\Pi}_{F, t}^{*}=$ $\tilde{P}_{H, t} / \tilde{P}_{F, t-1}^{*} ; w_{t}=W_{t} / P_{H, t} ; w_{t}^{*}=W_{t}^{*} / P_{F, t}^{*}$. Monetary Policy, resource constraints, production and price-dispersion equations:

$$
\begin{aligned}
& \frac{R_{t}}{\bar{R}}=\left(\frac{R_{t-1}}{\bar{R}}\right)^{\rho_{r}}\left(\left(\Pi_{H, t}\right)^{\phi_{\pi, h}}\left(\Pi_{F, t}^{*}\right)^{\phi_{\pi, f}}\left(\frac{Y_{t}}{\bar{Y}}\right)^{\phi_{y, h}}\left(\frac{Y_{t}^{*}}{\bar{Y}^{*}}\right)^{\phi_{y, f}}\right)^{1-\rho_{r}} \\
& \frac{R_{t}^{*}}{\bar{R}^{*}}=\left(\frac{R_{t}^{*}}{\bar{R}^{*}}\right)^{\rho_{r}}\left(\left(\Pi_{H, t}\right)^{\phi_{\pi, h}^{*}}\left(\Pi_{F, t}^{*}\right)^{\phi_{\pi, f}^{*}}\left(\frac{Y_{t}}{\bar{Y}}\right)^{\phi_{y, h}^{*}}\left(\frac{Y_{t}^{*}}{\bar{Y}^{*}}\right)^{\phi_{y, f}^{*}}\right)^{1-\rho_{r}} \\
& Y_{t}=\frac{\nu}{2} S_{t}^{1-\frac{\nu}{2}} C_{t}+\left(1-\frac{\nu}{2}\right) S_{t}^{\nu / 2} C_{t}^{*}+G_{t} \\
& Y_{t}^{*}=\left(1-\frac{\nu}{2}\right) S_{t}^{-\frac{\nu}{2}} C_{t}+\left(\frac{\nu}{2}\right) S_{t}^{\left(\frac{\nu}{2}-1\right)} C_{t}^{*}+G_{t}^{*} \\
& Y_{t}=\frac{N_{t}}{V_{t}} \\
& Y_{t}^{*}=\frac{N_{t}^{*}}{V_{t}^{*}} \\
& V_{t}=(1-\kappa)\left(\frac{\tilde{\Pi}_{H, t}}{\Pi_{H, t}}\right)^{-\theta}+\kappa \Pi_{H, t}^{\theta} V_{t-1} \\
& V_{t}^{*}=(1-\kappa)\left(\frac{\tilde{\Pi}_{F, t}^{*}}{\Pi_{F, t}^{*}}\right)^{-\theta}+\kappa \Pi_{F, t}^{*} V_{t-1}^{*}
\end{aligned}
$$


Household optimal equations and government budget constraints:

$$
\begin{aligned}
& N_{t}^{\sigma_{n}} C_{t}^{\sigma_{c}}=w_{t}\left(1-\tau_{t}\right) S_{t}^{\frac{\nu}{2}-1} \\
& \left(N_{t}^{*}\right)^{\sigma_{n}}\left(C_{t}^{*}\right)^{\sigma_{c}}=w_{t}^{*}\left(1-\tau_{t}^{*}\right) S_{t}^{1-\frac{\nu}{2}} \\
& C_{t}^{-\sigma_{c}}=\beta\left(\mathbb{E}_{t} Q_{t, t+1}\right)^{-1} \mathbb{E}_{t}\left\{\frac{C_{t+1}^{-\sigma_{c}}}{\Pi_{H, t+1}}\left(\frac{S_{t}}{S_{t+1}}\right)^{1-\frac{\nu}{2}}\right\} \\
& \left(C_{t}^{*}\right)^{-\sigma_{c}}=\beta\left(\mathbb{E}_{t} Q_{t, t+1}^{*}\right)^{-1} \mathbb{E}_{t}\left\{\frac{\left(C_{t+1}^{*}\right)^{-\sigma_{c}}}{\prod_{F, t+1}^{*}}\left(\frac{S_{t}}{S_{t+1}}\right)^{\frac{\nu}{2}-1}\right\} \\
& C_{t}^{-\sigma_{c}}=\left(C_{t}^{*}\right)^{-\sigma_{c}} S_{t}^{1-\nu} \\
& D_{t}^{n o r m}=R_{t} S_{t}^{\frac{\nu}{2}-1}\left(\frac{D_{t-1}^{n o r m} S_{t-1}^{1-\frac{\nu}{2}}}{\Pi_{H, t}}+G_{t}-\tau_{t} w_{t} N_{t}\right) \\
& D_{t}^{*, n o r m}=R_{t}^{*} S_{t}^{1-\frac{\nu}{2}}\left(\frac{D_{t-1}^{*, n o r m} S_{t-1}^{\frac{\nu}{2}-1}}{\Pi_{F, t}^{*}}+G_{t}^{*}-\tau_{t}^{*} w_{t}^{*} N_{t}^{*}\right)
\end{aligned}
$$

No-arbitrage conditions, fiscal rules and shocks:

$$
\begin{aligned}
& \ln \left(G_{t}\right)=\rho_{g} \ln \left(G_{t-1}\right)+\left(1-\rho_{g}\right) \ln (\bar{G})+\epsilon_{g} \\
& \ln \left(G_{t}^{*}\right)=\rho_{g} \ln \left(G_{t-1}^{*}\right)+\left(1-\rho_{g}\right) \ln \left(\bar{G}^{*}\right)+\epsilon_{g^{*}} \\
& R_{t}=\left(E_{t}\left\{Q_{t, t+1}\right\}\right)^{-1} \\
& R_{t}^{*}=\left(E_{t}\left\{Q_{t, t+1}^{*}\right\}\right)^{-1} \\
& \tau_{t}=\rho_{\tau} \tau_{t-1}+\left(1-\rho_{\tau}\right) \bar{\tau}+\left(1-\rho_{\tau}\right) \gamma_{\tau}\left(\frac{D_{t}}{Y_{t}}-\frac{\bar{D}}{\bar{Y}}\right) \\
& \tau_{t}^{*}=\rho_{\tau^{*}} \tau_{t-1}^{*}+\left(1-\rho_{\tau^{*}}\right) \bar{\tau}^{*}+\left(1-\rho_{\tau^{*}}\right) \gamma_{\tau^{*}}\left(\frac{D_{t}^{*}}{Y_{t}^{*}}-\frac{\bar{D}^{*}}{\bar{Y}^{*}}\right) \\
& \ln \left(A_{t}\right)=\rho_{A} \ln \left(A_{t-1}\right)+\epsilon_{A} \\
& \ln \left(A_{t}^{*}\right)=\rho_{A}^{*} \ln \left(A_{t-1}^{*}\right)+\epsilon_{A}^{*}
\end{aligned}
$$

For a total of 31 equations and 31 endogenous variables. ${ }^{1}$

\section{A.3}

\section{Ramsey-problem mathematically}

Define $\Xi_{t}=\left\{\Pi_{H, t}, X_{1, t}, X_{2, t}, C_{t}, Y_{t}, w_{t}, S_{t}, \tilde{\Pi}_{H, t}, \Pi_{F, t}^{*}, X_{1, t}^{*}, X_{2, t}^{*}, C_{t}^{*}\right.$, $\left.Y_{t}^{*}, w_{t}^{*}, \tilde{\Pi}_{F, t}^{*}, N_{t}, N_{t}^{*}, V_{t}, V_{t}^{*}, D_{t}^{\text {norm }}, D_{t}^{*, n o r m}, \tau_{t}, \tau_{t}^{*}, R_{t}, R_{t}^{*}\right\}$ and $\Upsilon_{t}$ equal the set of equations $\{(\mathrm{A}-1)-(\mathrm{A}-8),(\mathrm{A}-11)-(\mathrm{A}-23)\}$ at period t. ${ }^{2}$ Then the Ramseyproblem may be stated as:

\footnotetext{
${ }^{1}$ In this sentence we also denoted as endogenous variables the ones that follow a law of movement - $A_{t}, A_{t}^{*}, G_{t}, G_{t}^{*}$ - for the purpose of counting.

${ }^{2}$ Notice that we do not consider equations (A-9), (A-10) and (A-24)-(A-31). Consider that we already substituted equations (A-26), (A-27) into (A-19), (A-20) respectively.
} 


$$
\begin{array}{ll}
\max _{\left\{\Xi_{t}\right\}_{t=0}^{\infty}} & \sum_{t=0}^{\infty} \beta^{t}\left\{U\left(C_{t}\right)-V\left(N_{t}\right)+J\left(G_{t}\right)+U\left(C_{t}^{*}\right)-V\left(N_{t}^{*}\right)+J\left(G_{t}^{*}\right)\right\} \\
\text { s.t. } & \sum_{t=0}^{\infty} \beta^{t}\left\{\Upsilon_{t}\right\}
\end{array}
$$

For a total of 25 endogenous variables and 21 equations. The instruments are $\left\{R_{t}, R_{t}^{*}, \tau_{t}, \tau_{t}^{*}\right\}$ and the other 21 variables are functions of these four. We also have 21 lagrange multipliers (one for each equation). To find the Ramsey steady-state we first need to compute the 25 first order conditions for the endogenous variables plus the 21 constraints and, ater that, drop the time-index from all variables. This is a cumbersome problem and we don't solve it analytically here, instead we rely on Dynare's embedded function ramsey_policy where we indicate the steady-state with $R=R^{*}=1 / \beta$, $\Pi_{H}=\Pi_{F}^{*}=1, S=1, D=D^{*}=0$ and let the routine calculate numerically the optimal steady-state based on this indication. Indeed this is the steadystate chosen, so appendix D presents the relations that are satisfied in the Ramsey steady-state.

\section{A.4}

\section{Steady State}

Here we define the steady state values of the main variables. First, from social-planner's problem we see that for this steady state to be efficient we need to define $\chi$ and $\chi^{*}$ such that the monopoly and income tax distortions are offset and (2-7) holds. In a flexible-price equilibrium, with $\kappa=0$, we have $P_{H, t}(i)=P_{H, t}, P_{F, t}(i)=P_{F, t}, V_{t}=V_{t}^{*}=1$. From the firms profit maximization problem, equation (2-6), we have $P_{H, t}=A^{-1} W_{t}(1-\chi) \frac{\theta}{\theta-1}$ and $P_{F, t}^{*}=A^{-1} W_{t}^{*}\left(1-\chi^{*}\right) \frac{\theta}{\theta-1}$. By setting:

$$
\begin{aligned}
& \frac{(1-\chi)}{(1-\bar{\tau}) \frac{\theta-1}{\theta}}=1 \Rightarrow \chi=1-\left(1-\bar{\tau}^{N}\right) \frac{\theta-1}{\theta} \\
& \frac{\left(1-\chi^{*}\right)}{\left(1-\bar{\tau}^{*}\right) \frac{\theta-1}{\theta}}=1 \Rightarrow \chi^{*}=1-\left(1-\bar{\tau}^{*, N}\right) \frac{\theta-1}{\theta}
\end{aligned}
$$

Now for the other variables we look for a symmetric equilibrium such that $\bar{S}=1$. From (2-2) and the foreign analogous, using the values above we get:

$$
U_{c}(\bar{C})=V_{n}(\bar{N}) ; \quad U_{c}\left(\bar{C}^{*}\right)=V_{n}\left(\bar{N}^{*}\right)
$$

From (2-5) we get:

$$
U_{c}(\bar{C})=U_{c}\left(\bar{C}^{*}\right) \Rightarrow \bar{C}=\bar{C}^{*}
$$

and this implies:

$$
\bar{N}=\bar{N}^{*}
$$

From market clearing equations we get: 


$$
\bar{N}=\bar{C}+\bar{G} ; \quad \bar{N}^{*}=\bar{C}^{*}+\bar{G}^{*} \Rightarrow \bar{G}=\bar{G}^{*}
$$

From euler equations we get:

$$
\bar{R}=\bar{R}^{*}=\frac{1}{\beta}
$$

We assume that the steady state government debt is zero (i.e $\bar{D}=\bar{D}^{*}=0$ ), and therefore we get from governments budget constraints:

$$
\bar{\tau}=\frac{\frac{\bar{G}}{\bar{N}}}{1+\frac{\bar{G}}{N}}=\frac{\frac{\bar{G}^{*}}{N^{*}}}{1+\frac{\bar{G}^{*}}{\bar{N}^{*}}}=\bar{\tau}^{*}
$$

\section{A.5 \\ Robustness Exercise}

In this section we show the results of the Ramsey-problem when the welfare measure is given by (3-11). Figures (A.1) and (A.2) stand for the lump-sum case, and figures (A.3) and (A.4) are relative to the income-tax case. In both scenarios we see that after a positive home technology shock the mechanism of section 4 is presented: Consumption rises, home output rises and foreign output falls, hours worked falls and the terms $\mathrm{f}$ trade depreciate ${ }^{3}$. Pertaining policy responses, both countries engage in a expansionary monetary policy, but this time, home country produces inflation so as to channel consumption into foreign country. This has the effect of creating a lower level of inflation in the foreign country (which is only partially offset by the foreign authority monetary policy) counteracting the rise in real wage to induce a raise in the supply of labour and production. With income-taxation there is an additional effect on inflation and the terms of trade: the foreign tax falls inducing deflation and a home terms of trade appreciation (compared to the lump-sum case), i.e. channelling demand to foreign country. Home country also lowers taxes, and this might be due to consumption effects, as consumption is equated across countries and a rise in home (and consequently foreign) consumption is welfare improving. ${ }^{4}$ The overall effect is a more appreciated terms of trade in the income-tax case, then in the lump-sum case, accounting for the terms of trade externality as exposed in Benigno and De Paoli (2006).

\footnotetext{
${ }^{3}$ This effects alone are due to the techonolgy shock

${ }^{4}$ As it is a home country positive technology shock supply effects are stronger in this country.
} 

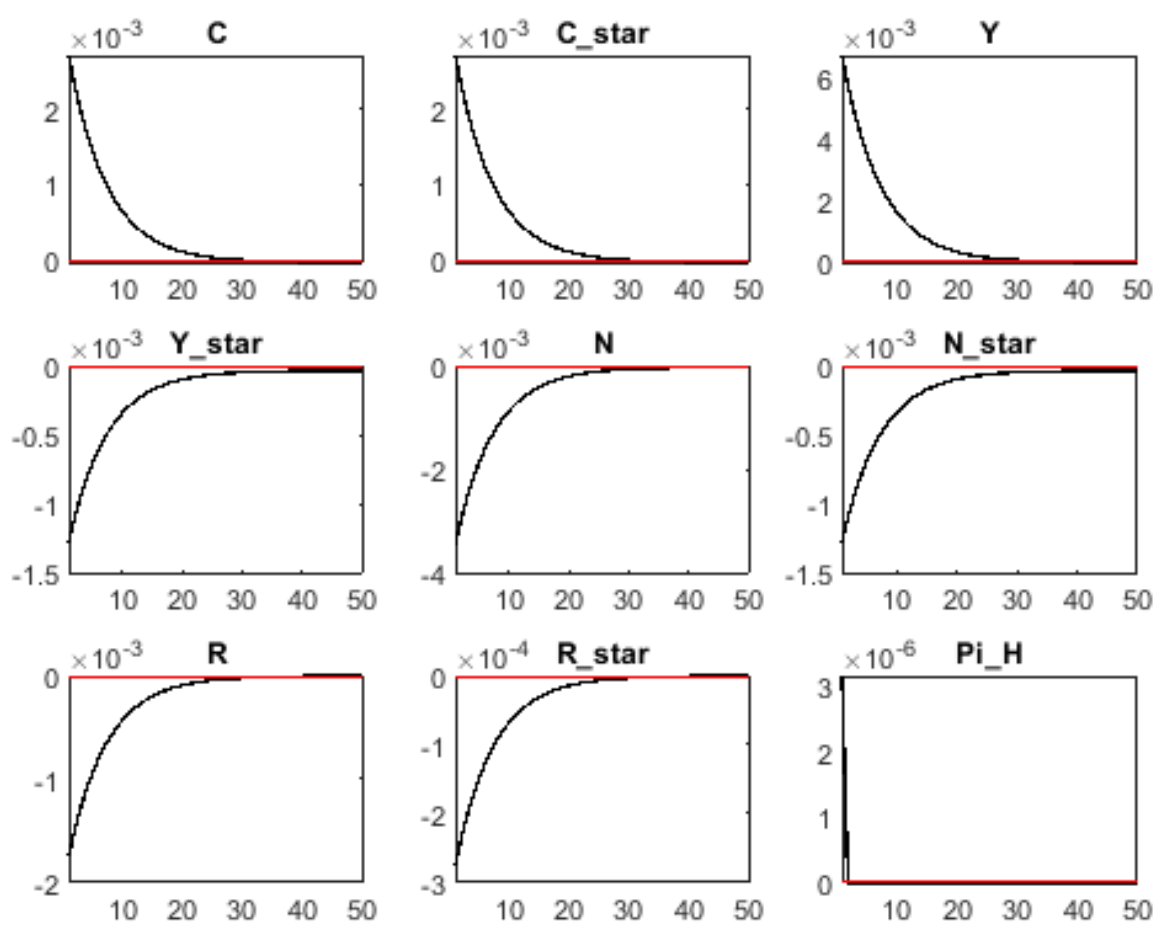

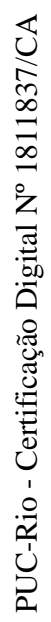

Figure A.1: IRFs when welfare is given by (3-11) - Distortionary-tax case
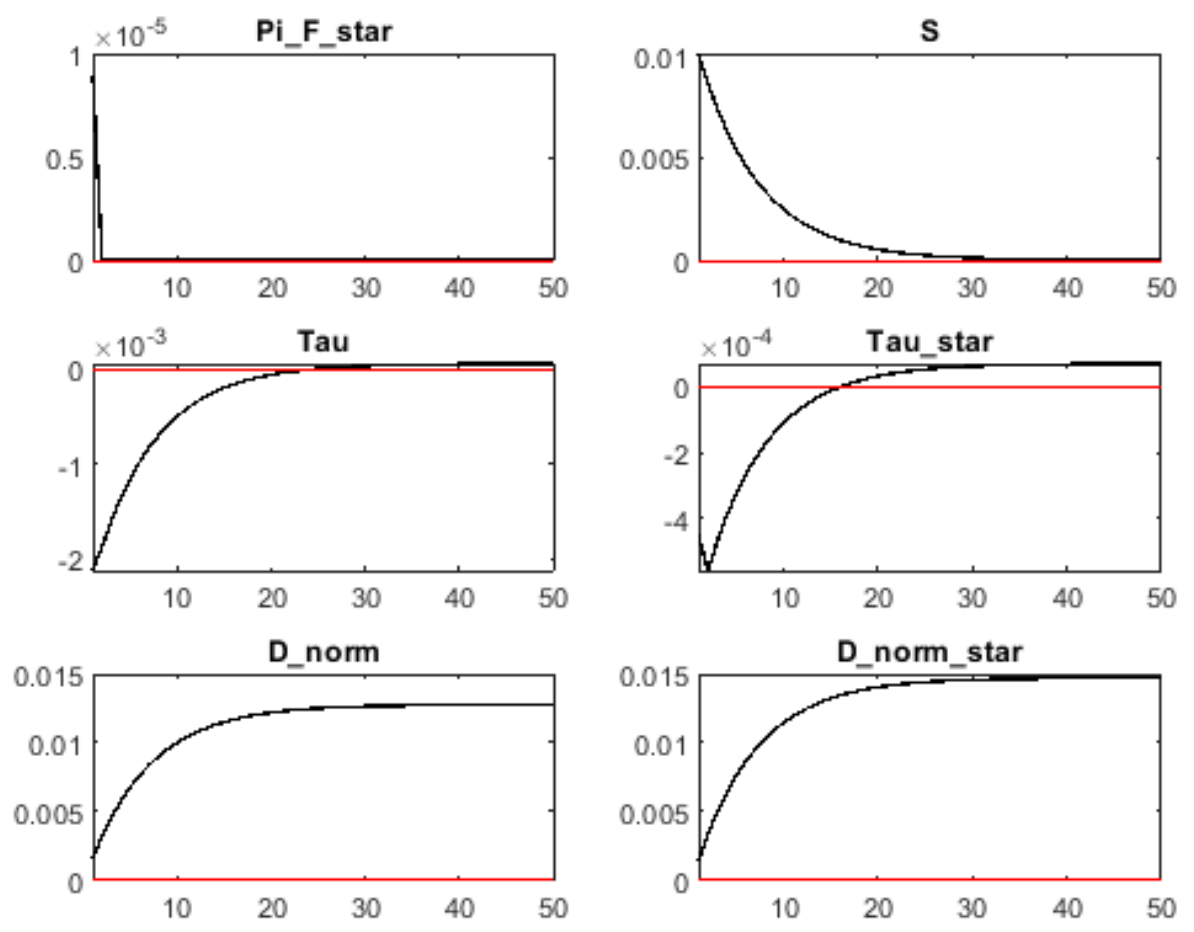

Figure A.2: IRFs when welfare is given by (3-11) - Distortionary-tax case 

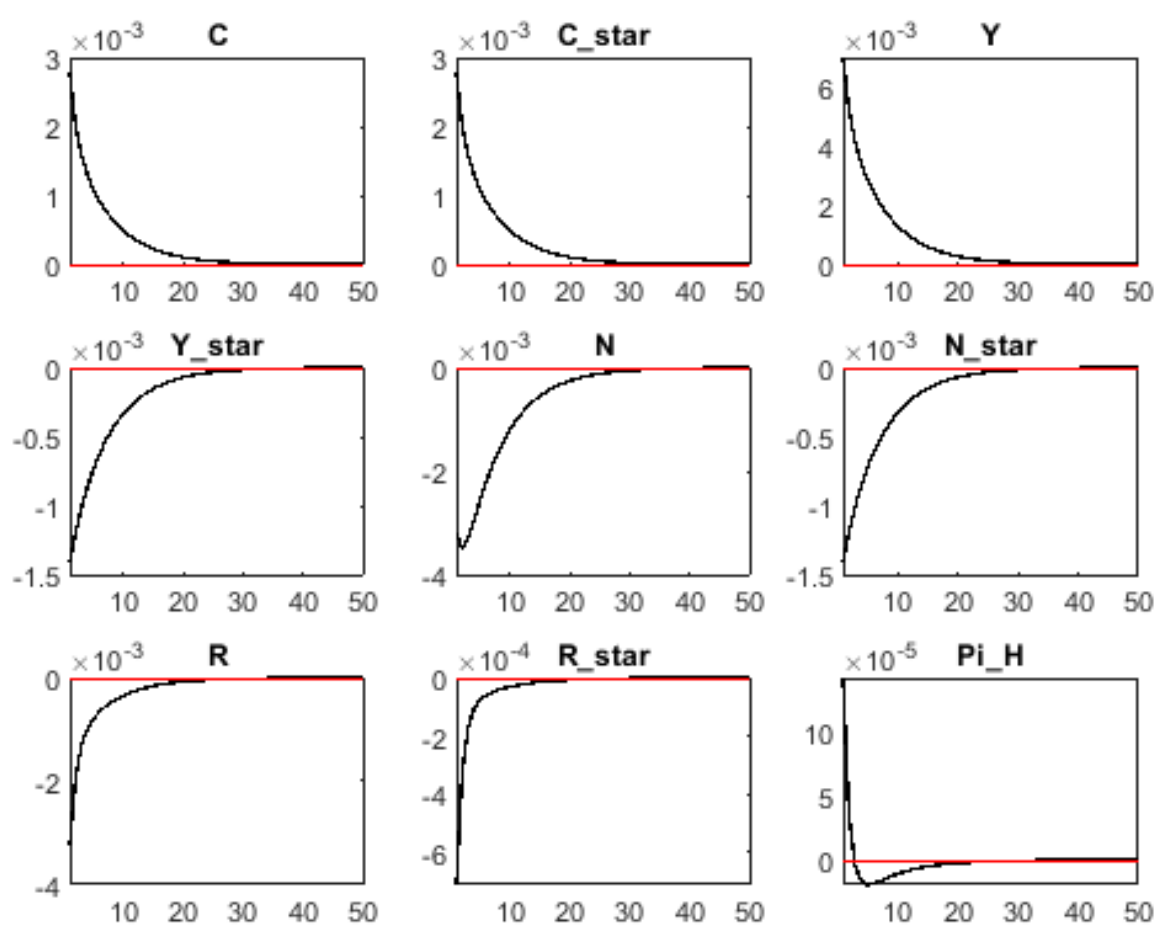

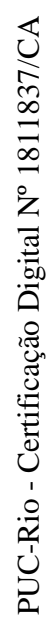

Figure A.3: IRFs when welfare is given by (3-11) - Lump-sum case
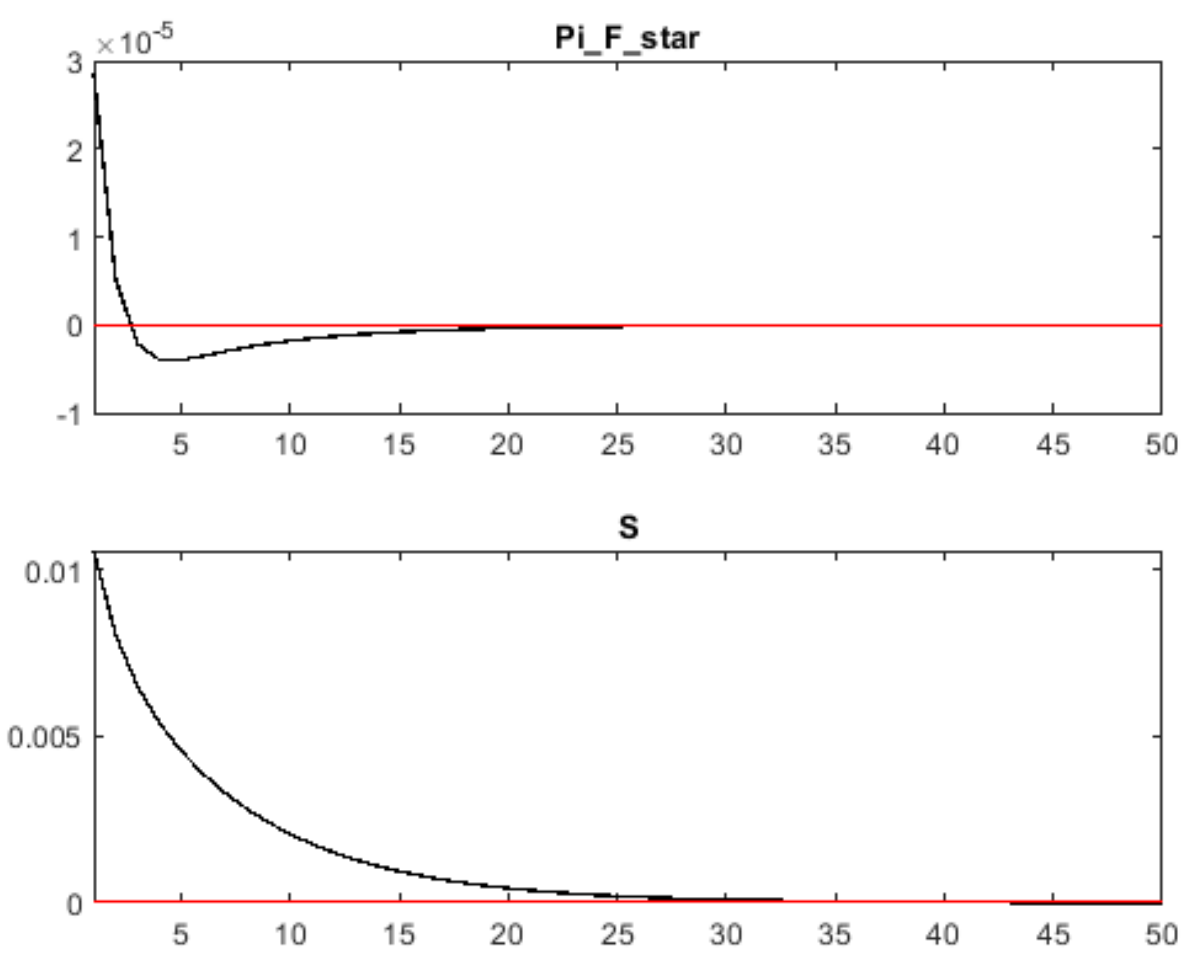

Figure A.4: IRFs when welfare is given by (3-11) - Lump-sum case 